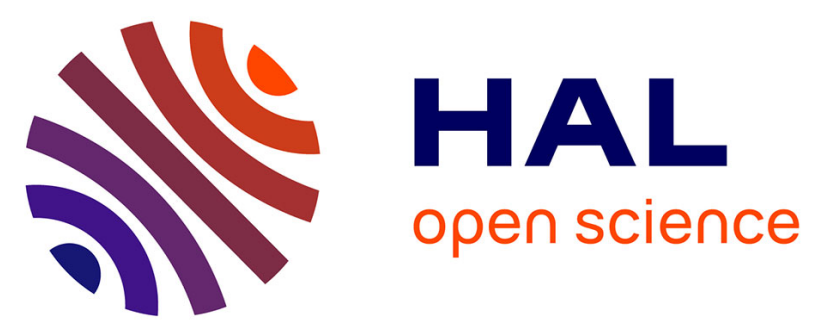

\title{
Chemical and optical characterization of aerosols measured in spring 2002 at the ACE-Asia supersite, Zhenbeitai, China
}

S. Alfaro, L. Gomes, J.L. Rajot, S. Lafon, A. Gaudichet, B. Chatenet, M. Maille, G. Cautenet, F. Lasserre, H. Cachier, et al.

\section{To cite this version:}

S. Alfaro, L. Gomes, J.L. Rajot, S. Lafon, A. Gaudichet, et al.. Chemical and optical characterization of aerosols measured in spring 2002 at the ACE-Asia supersite, Zhenbeitai, China. Journal of Geophysical Research, 2003, 108 (D23), 10.1029/2002JD003214 . hal-03132168

\section{HAL Id: hal-03132168 https://hal.science/hal-03132168}

Submitted on 5 Feb 2021

HAL is a multi-disciplinary open access archive for the deposit and dissemination of scientific research documents, whether they are published or not. The documents may come from teaching and research institutions in France or abroad, or from public or private research centers.
L'archive ouverte pluridisciplinaire HAL, est destinée au dépôt et à la diffusion de documents scientifiques de niveau recherche, publiés ou non, émanant des établissements d'enseignement et de recherche français ou étrangers, des laboratoires publics ou privés. 


\title{
Chemical and optical characterization of aerosols measured in spring 2002 at the ACE-Asia supersite, Zhenbeitai, China
}

\author{
S. C. Alfaro, ${ }^{1}$ L. Gomes, ${ }^{2}$ J. L. Rajot, ${ }^{3}$ S. Lafon, ${ }^{1}$ A. Gaudichet, ${ }^{1}$ B. Chatenet, ${ }^{1}$ \\ M. Maille, ${ }^{1}$ G. Cautenet, ${ }^{4}$ F. Lasserre, ${ }^{4}$ H. Cachier, ${ }^{5}$ and X. Y. Zhang ${ }^{6}$ \\ Received 25 November 2002; revised 29 April 2003; accepted 12 May 2003; published 10 October 2003.
}

[1] In April 2002, aerosol characteristics have been recorded at Zhenbeitai (ZBT) near the city of Yulin $\left(38^{\circ} 17^{\prime} \mathrm{N}, 109^{\circ} 43^{\prime} \mathrm{E}\right.$, Shaanxi province, China). One year earlier, ZBT had been one of the continental supersites of the ACE-Asia international experiment. In spring, this site, located on the southwestern fringe of the Mu Us desert, is at the crossing of the pathways followed by dust originating from the main Chinese dust sources. During the experiment a customized aerosol sampler has been used. It had been specially designed to ensure the best possible sampling isokineticity for all instruments and to minimize coarse particle losses. Its cutoff size $\left(D_{50}\right)$ has been computed to be $9 \mu \mathrm{m}$. For particles smaller than this size (PM9), mass concentrations, number concentrations, size distributions, elemental composition, and scattering properties were measured at ground level. Vertically integrated characteristics such as aerosol optical thickness (AOT), or single scattering albedo $\left(\varpi_{0}\right)$, were also determined by the means of a Sun-tracking photometer. During the measurement period, several dust events, one of them a major dust storm when PM9 mass concentrations became as high as $4650 \mu \mathrm{g} / \mathrm{m}^{3}$, were observed. At this time the aerosol scattering coefficient reached $2800 \mathrm{Mm}^{-1}$. These dust events were separated by periods when optical properties were altered, or even dominated, by anthropogenic aerosol of local origin. For these periods, PM9 was significantly less (always below $100 \mu \mathrm{g} / \mathrm{m}^{3}$ ) than during dust events, mass concentration in black carbon (BC) was between 0.9 and $6.7 \mu \mathrm{g} /$ $\mathrm{m}^{3}$, and the aerosol scattering coefficient between 7 and $800 \mathrm{Mm}^{-1}$. No difference in elemental composition could be detected between the various dust episodes. Measured $\mathrm{Fe} /$ $\mathrm{Al}(0.63 \pm 0.04)$ and $\mathrm{Mg} / \mathrm{Al}(0.32 \pm 0.03)$ ratios are consistent with an aerosol source located in the "northwestern high desert sources." This result is also supported by the air mass back-trajectories coming from a west or northwest direction and by the fact that dust layers had generally already acquired a significant vertical extension $(\sim 1500 \mathrm{~m})$ when reaching the measurement site. This transported dust had already incorporated an anthropogenic carbonaceous component upon reaching the measurement site. The size distribution of this transported mixture is relatively constant and is characterized by the presence of a particle population with a number mean diameter between 1 and $2 \mu \mathrm{m}$. The mass scattering efficiency of this aerosol is $1.05 \pm 0.13 \mathrm{~m}^{2} / \mathrm{g}$, relative to PM9, and its Angström exponent is close to 0.19 . The single scattering albedo determined by data inversion of Sun photometer measurements is found to increase from 0.89 at $441 \mathrm{~nm}$ to 0.95 at $873 \mathrm{~nm}$. These relatively large $\varpi_{0}$ values indicate that, though mixing of mineral dust and anthropogenic aerosols is the rule rather than the exception at ZBT, the aerosol is still not very absorbent during intense dust events. In consequence, the dust optical characteristics measured at ZBT during dust storms are probably representative of the ones of pure dust emitted from the "northwestern high desert" sources. INDEX TERMS: 0305 Atmospheric Composition and Structure: Aerosols and particles (0345, 4801); 3025 Marine Geology and

\footnotetext{
${ }^{1}$ Laboratoire Inter-universitaire des Systemes Atmospheriques, Université Paris VII/Paris XII, Créteil, France.

${ }^{2}$ Meteo-France, Centre National de la Recherche Meteorologique, Groupe de Meteorologie Experimentale et Intrumentale, Toulouse, France.

${ }^{3}$ Institut de Recherche et Developpement, Laboratoire Inter-universitaire des Systemes Atmospheriques, Unite Mixte de Recherche, Centre

Copyright 2003 by the American Geophysical Union. 0148-0227/03/2002JD003214
}

National de la Recherche Scientifique, Université Paris VII/Paris XII, Créteil, France.

${ }^{4}$ Laboratoire de Meteorologie Physique, Université Blaise Pascal, Aubière, France.

${ }^{5}$ Laboratoire des Sciences du Climat et de l'Environnement, Commissariat a l'Energie Atomique, Centre National de la Recherche Scientifique, Gif/Yvette Cedex, France.

${ }^{6}$ State Key Laboratory of Loess and Quaternary Geology, Institute of Earth Environment, Chinese Academy of Science, Xi'An, China. 
Geophysics: Marine seismics (0935); 0330 Atmospheric Composition and Structure: Geochemical cycles; 0345 Atmospheric Composition and Structure: Pollution — urban and regional (0305); KEYWORDS: ACE-Asia, China, mineral dust, chemical composition, optical properties

Citation: Alfaro, S. C., et al., Chemical and optical characterization of aerosols measured in spring 2002 at the ACE-Asia supersite, Zhenbeitai, China, J. Geophys. Res., 108(D23), 8641, doi:10.1029/2002JD003214, 2003.

\section{Introduction}

[2] In climate modeling one of the main sources of uncertainty is linked to the poor representation of the part played by natural aerosols [Intergovernmental Panel on Climate Change (IPCC), 2001]. By scattering and absorbing solar and/or thermal radiation, these particles alter radiative transfer through the atmosphere. In the case of purely anthropogenic aerosols, an assessment of the source locations, intensities and initial particle characteristics can be made. After modeling transport and optical properties of these aerosols, using radiative transfer codes makes it possible to determine their impact on climate with relatively good precision. This is not as easy in the case of wind driven emissions (sea salt, mineral dust) that are highly sporadic in time and space. Moreover, in the case of mineral dust that represents about half the mass of all aerosols injected each year into the troposphere [Andreae, 1995], the initial aerosol characteristics (emission flux, size distribution, mineral and chemical composition, shape, etc.) depend on the surface features in source areas and on the aerodynamic conditions prevailing during emissions.

[3] At such a level of complexity it is necessary to develop physically explicit dust emission models able to locate sources and provide all the particles initial characteristics at the same time. Such a complete model does not yet exist. Still, in its current state of development the dust production model (DPM) [Alfaro and Gomes, 2001] already allows computation of emission intensities and size distributions at the source. The DPM has been combined to the Regional Atmospheric Modeling System (RAMS) model of the Colorado State University [Pielke and Mahrer, 1975]. Details of the coupling with the DPM may be found in the work of Cautenet et al. [2000]. Thanks to this coupling it becomes possible to predict mineral dust concentration and size distribution at any time and at distances up to thousands of kilometers from the source. By assuming a particle composition, or equivalently an average refraction index, the spatial distribution of aerosol optical properties can then be derived from Mie theory. In order to constrain and validate these computations it is important to compare concentrations, size distributions, and optical properties predicted by the model to direct measurements. Documenting the chemical and mineralogical composition, as well as the shape of particles, in a region as close as possible to the actual dust sources is also necessary to minimize computational uncertainties, and to complete the DPM.

[4] In Spring 2001, the ACE-Asia international experiment was carried out in eastern Asia. One of the objectives of this experiment was to determine the physical, chemical, and radiative properties of the major aerosol types in order to assess their regional direct and indirect radiative forcing. Aerosol characteristics were measured in April 2001 (J. Xu et al., Aerosol radiative properties and direct radiative forcing near a desert source region of northwest China during ACE-Asia, submitted to Journal of Geophysical Research, 2003, hereinafter referred to as Xu et al., submitted manuscript, 2003) in the vicinity of Yulin (Shaanxi province, China) which is located at the interface of the Gobi desert and the Loess Plateau (Figure 1). One year after this experiment, this continental ACE-Asia supersite has been reactivated. Indeed, this site has been chosen again because in springtime the pathways of dust emitted from major Chinese dust sources converge here, and the probability of observing mineral dust from the Gobi and adjacent deserts is at its highest [Parungo et al., 1994; Sun et al., 2001]. After describing the site and experimental setup, the aims of this paper are to (1) analyze variations in observed aerosol optical properties in relation with changes in aerosol characteristics (composition, concentrations, and size-distributions), and (2) provide the optical properties of the main (mineral dust and anthropogenic) individual aerosol components. Comparing these results with predictions of the DPM/RAMS combination is the object of a future paper (G. Cautenet et al., manuscript in preparation, 2003).

\section{Experimental Setup}

\subsection{Experimental Sites}

[5] Like in 2001, the 2002 experiment took place at Zhenbeitai on the aerosol monitoring station operated by the Institute of Earth Environment of Chinese Academy of Science (IEECAS). All the instruments used for determining the aerosol composition and optical properties at ground level were implemented at a height of $10 \mathrm{~m}$ on the first stage of a $20 \mathrm{~m}$ tower. This experimental site is located about $10 \mathrm{~km}$ north of the city of Yulin at an elevation of about $1100 \mathrm{~m}$ above sea level. (ZBT, $\left.38^{\circ} 17^{\prime} \mathrm{N}, 109^{\circ} 43^{\prime} \mathrm{E}\right)$. It is at the limit of a vast arid area including the $\mathrm{Mu}$ Us desert at the west, the Hodq desert at the northwest, and arid Inner Mongolia dry lands at the north (Figure 1).

[6] A Sun photometer of the PHOTONS network (the French part of the Aerosol Robotic Network, AERONET) was also set up in downtown Yulin on the roof of the Shaanxi Province Institute of Desert Control (SPIDC, elevation $1060 \mathrm{~m}$ ). It was used to measure aerosol optical properties integrated vertically over the height of the atmosphere.

\subsection{Instruments and Methods}

\subsubsection{Aerosol Origin}

[7] For determining the origin of air masses sampled at ZBT and their possible implications on the aerosol properties, wind direction and speed were monitored continuously between 31 March and 23 April 2002, with a model W200P (vector instrument) wind vane and a model A100R (vector instrument) anemometer. A combined probe (model HMP $35 \mathrm{AC}$, Vaisala) also recorded humidity and temperature variations. To determine the aerosol origin at a larger space and timescales, back-trajectories of air masses sampled at 


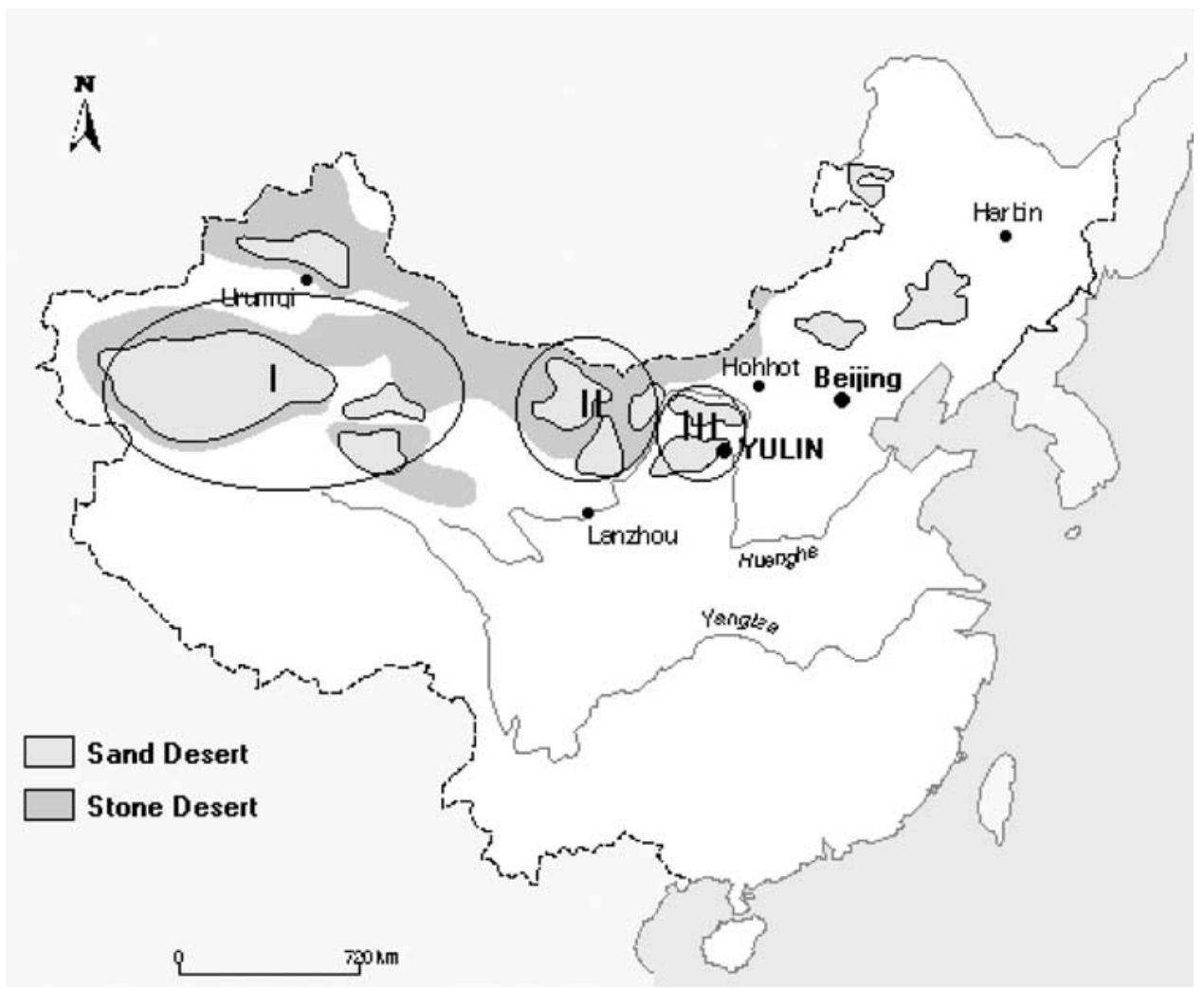

Figure 1. Map of China showing the location of the experimental site and of the main sand and stone paved (gobi) deserts. Three main potential dust sources identified by Zhang et al. [1996] have also been reported (zones I to III). Zone I approximately corresponds to Taklamakan desert, zone II is the so-called "northwestern high desert," and zone III includes the Hodq and Mu Us deserts at the southwestern limit of which Yulin is located.

ZBT were computed. For this, a simple scheme consisting in integrating the 3-D kinematic equations has been used. The $3-\mathrm{D}$ velocity field necessary for this procedure originates from the standard ECMWF analysis. In order to avoid truncating errors, the successive positions of a particle are retrieved backward at a small time step (10 min) (Y. Pointin, personal communication, 2002).

\subsubsection{Aerosol Collection}

[8] During the sampling period, all the instruments and sampling lines used at ZBT were connected to a unique aerosol collector (Figure 2) in order to ensure consistency of measurements by the different instruments. Air was sucked at a constant flow rate $\left(50 \mathrm{~m}^{3} /\right.$ hour $)$ through a rotating sampling head equipped with a vane to make it face the wind. The air speed at the entrance of the sampling head is $12.2 \mathrm{~m} / \mathrm{s}$, a value that was chosen slightly larger than the expected order of magnitude of the wind speed at $10 \mathrm{~m}$ above ground $(\sim 10 \mathrm{~m} / \mathrm{s})$, thus minimizing errors due to subisokinetic sampling.

[9] The exit of the sampling head is connected to a vertical cylinder having a diameter of $14 \mathrm{~cm}$, ensuring a Reynolds' number value close to 10000 in this part of the system. Thus the turbulence of the flow helps homogenize transversal concentrations of aerosol particles before they reach the cylinder cross section where sampling by the instruments is performed.

[10] Several individual tubes facing the flow and parallel to the axis of main cylinder are used for this sampling. Their individual inner diameters have been computed according to the instruments nominal flow rates to ensure isokineticity of the particle collection in this part of the system.

[11] It has to be noted that the sampling system and its operating conditions were designed to minimize particle losses in all size classes. This is particularly important for studying the properties of mineral dust that is known to include an important fraction located in the supermicron size range, but also of a significant submicron one [Gomes et al., 1990; Alfaro et al., 1998]. However, because there is a bend in the inlet of the aerosol collector losses by impaction of coarse particles are expected. For our experimental conditions, Willeke and Baron [1993, equation (6-53)] allow computation of the inlet collection efficiency as a function of particle size. It is found (Figure 3) that the probability for particles smaller than $9 \mu \mathrm{m}$ (PM9) to enter the system is larger than $50 \%$. Classically, this defines the aerosol collector size cutoff.

\subsubsection{Concentrations and Composition}

[12] A Tapered Element Oscillating Microbalance (TEOM, model 1400a, Rupprecht and Patashnick) operated at a controlled flow rate of $3 \mathrm{~L} / \mathrm{min}$ was used to record continuously PM9 mass concentrations averaged over 15 min periods between 9 and 21 April.

[13] In parallel, three types of sampling lines were operated at a flow rate of $10 \mathrm{~L} / \mathrm{min}$ between 31 March and 24 April. The first one was used to collect aerosol particles on $0.4 \mu \mathrm{m}$ Nuclepore filters (50 samples) with the main aim of deter- 


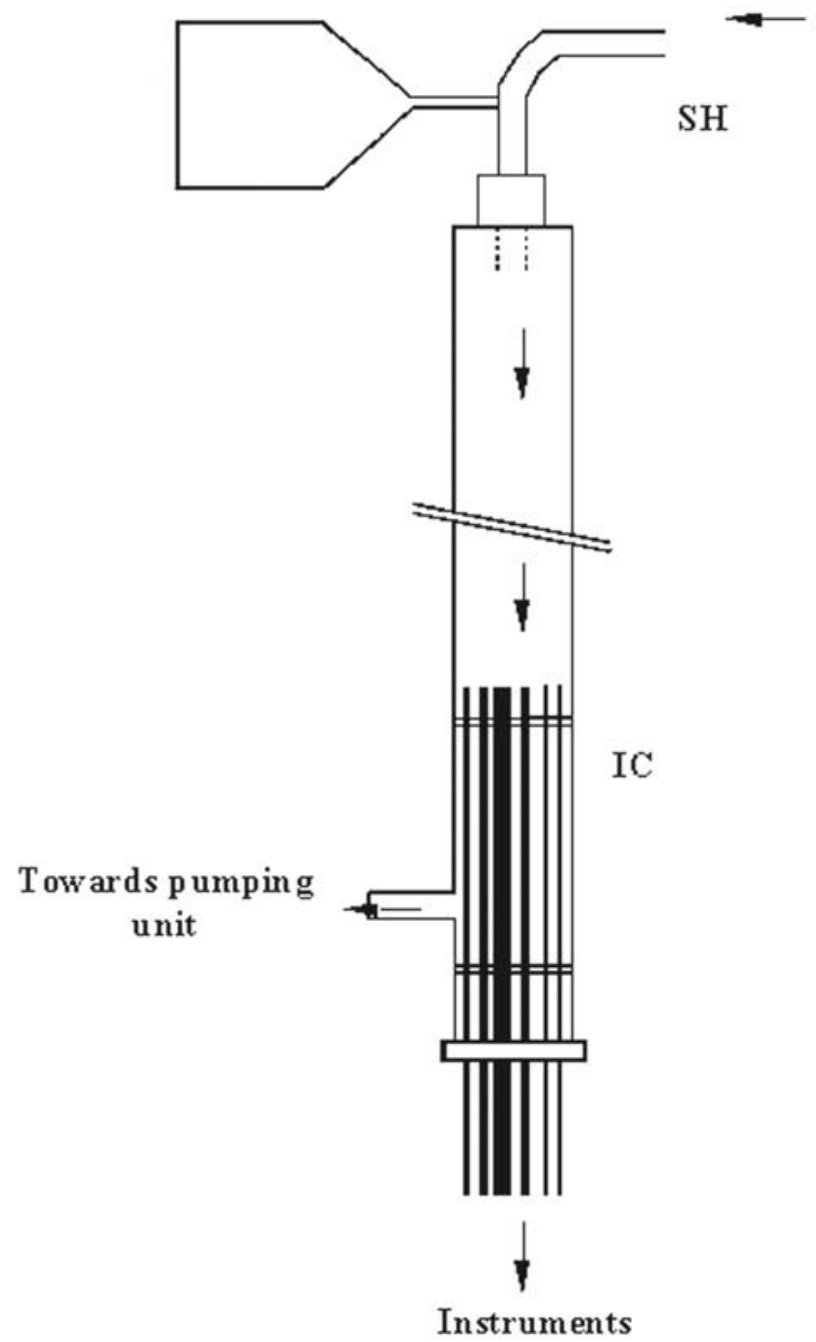

Figure 2. Scheme of the sampler specially designed for collecting aerosol particles properties (see text for details).

mining concentrations in major and minor elements ( $\mathrm{Si}, \mathrm{Al}$, $\mathrm{Ca}, \mathrm{Fe}, \mathrm{Mg}, \mathrm{K}, \mathrm{Na}, \mathrm{Cl}$, Ti, P, Mn, S) by X Ray Fluorescence (XRF) analysis as described by Losno et al. [1987]. The sampling time was adjusted according to the PM9 concentration measured in real time by the TEOM, and ranged from $30^{\prime}$ or less during dust storms to 13 hours in the cleanest conditions. Time series of concentrations in typically crustal elements such as $\mathrm{Al}$ are useful to identify dust events among the PM9 peaks detected by the TEOM. Results of XRF analysis for these dust periods provide elemental composition of mineral dust. The second sampling line was used for collecting, on the same type of filters, samples to be observed under scanning or transmission electron microscope (SEM or TEM). This allows 1) direct determination of the size and shape of aerosol particles, and 2) assessment of the sizeresolved chemical and mineralogical composition of aerosol particles when coupled to energy dispersive spectrometry of $\mathrm{X}$-Rays (EDS). These analysis are presently under way, and their results will be presented in a future paper.

[14] The purpose of the third sampling line was to determine atmospheric concentrations in total carbon (TC), black carbon (BC), and organic carbon (OC). For this, 16 aerosol samples collected during longer periods (from 12 hours to 48 hours) on precleaned Whatman quartz fiber filters were submitted, after decarbonation by prolonged contact with $\mathrm{HCl}$ fumes, to thermal analysis according to the method described by Cachier et al. [1989]. The decarbonation step is particularly crucial because Chinese soils are known to be rich in carbonates [Xuan and Sokolik, 2002]. Finally, the method yields TC and BC, and OC is computed as the difference between TC and BC.

\subsubsection{Aerosol Size Distributions}

[15] Between 31 March and 23 April, aerosol number size distributions were monitored every $15 \mathrm{~min}$ with an optical size analyzer (OSA, model MET ONE 237B). To avoid saturation during strong dust events, an air diluter (Topas, model DIL 550) reducing concentrations by a factor 100 was systematically used before particles were counted in the 6 diameter classes $(0.3-0.5,0.5-0.7,0.7-1.0,1.0-2.0$, $2.0-5.0,>5.0 \mu \mathrm{m})$ of the OSA. The OSA and diluter were operated at their nominal flow rate $(2.8 \mathrm{~L} / \mathrm{min})$.

\subsection{Aerosol Optical Properties}

\subsubsection{Nephelometer Measurements}

[16] At ground level, the aerosol scattering coefficients integrated between 7 and $170^{\circ}\left(\sigma_{\text {neph }, \lambda}\right)$ were measured between 31 March and 24 April at three wavelengths $(450,550$, and $700 \mathrm{~nm})$ by a nephelometer (TSI, model 3563) fully described by Bodhaine et al. [1991]. At a given wavelength $(\lambda)$, these scattering coefficients are extensive quantities that increase with the aerosol concentration but also depend on its particle size distribution and refractive index. Indeed, they can be expressed as

$$
\sigma_{\text {neph }, \lambda}=\int_{d=0}^{\infty} \mathrm{f}(\mathrm{d}, \lambda, \mathrm{n}) \sigma_{\mathrm{N}, \text { scatt }, \lambda}(\mathrm{d}, \mathrm{n}) \frac{\mathrm{dN}}{\mathrm{d} \log (\mathrm{d})} \mathrm{d} \log (\mathrm{d})
$$

where $\sigma_{\mathrm{N}, \text { scatt, } \lambda}$ (in $\mathrm{m}^{2}$ ) is the particular scattering cross section depending on particle size (d) and complex refractive index $(\mathrm{n}), \mathrm{dN}$ is the number concentration for particles with a logarithmic diameter between $\log (\mathrm{d})$ and $\log (d)+d \log (d)$, and $f(d, \lambda, n)$ is the efficiency of the nephelometer to detect light scattered in all directions by particles of size $d$ and refractive index $n$. Since, for geometrical reasons detailed by Bodhaine et al. [1991], the

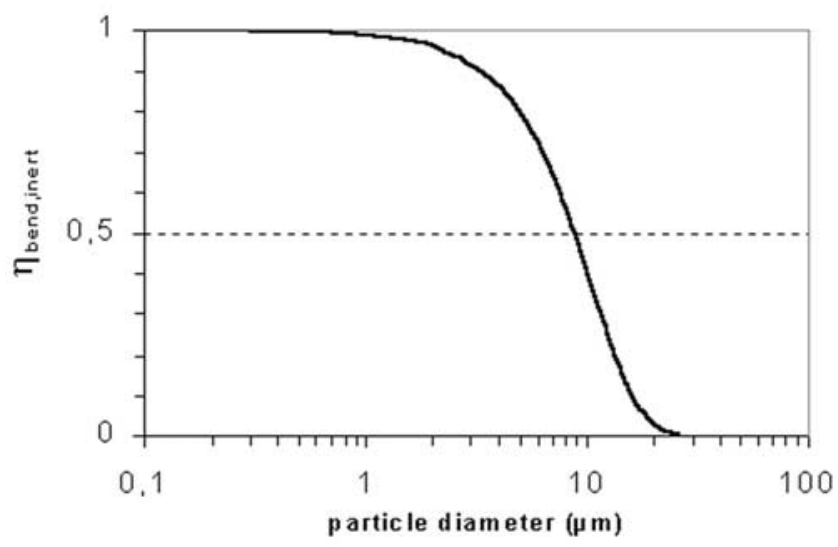

Figure 3. Collection efficiency of the inlet of the aerosol collector as a function of particle size (see text for details). 
Table 1. Particle Scattering Cross Sections $\left(\sigma_{\mathrm{N}, \mathrm{scatt}, \lambda}\right)$ and Nephelometer Efficiencies (f) Computed at 450 and $700 \mathrm{~nm}$ for Each Size Class of the OSA ${ }^{\mathrm{a}}$

\begin{tabular}{|c|c|c|c|c|c|c|}
\hline$\lambda, \mathrm{nm}$ & Size Class, $\mu \mathrm{m}$ & $0.3-0.5$ & $0.5-0.7$ & $0.7-1.0$ & $1.0-2.0$ & $2.0-5.0$ \\
\hline 450 & $\sigma_{\mathrm{N}, \mathrm{scat}, \lambda}\left(10-{ }^{12} \mathrm{~m}^{2}\right)$ & 0.398 & 1.05 & 1.20 & 3.62 & 16.3 \\
\hline- & f (\%) & 96.3 & 92.8 & 89.8 & 73.4 & 40.9 \\
\hline 700 & $\sigma_{\mathrm{N}, \text { scatt }, \lambda}\left(10-{ }^{12} \mathrm{~m}^{2}\right)$ & 0.188 & 0.907 & 2.18 & 2.93 & 18.4 \\
\hline- & $\mathrm{f}(\%)$ & 98.1 & 96.4 & 93.8 & 89.3 & 52.4 \\
\hline
\end{tabular}

${ }^{\mathrm{a}}$ The particle complex refractive index used for the computations is the one of mineral dust $(\mathrm{n}=1.55-0.01 \mathrm{i})$.

nephelometer misses the $0-7^{\circ}$ forward diffusion peak and the light backscattered in the $170-180^{\circ}$ range $\mathrm{f}(\mathrm{d}, \lambda, \mathrm{n})$ is less than 1. More precisely, Mie theory shows that the nephelometer truncation effect increases with $d$. As a result, $\mathrm{f}(\mathrm{d}, \lambda, \mathrm{n})$ is a decreasing function of particle size (Table 1). In other words, the coarser the particles, the worse their contribution to aerosol scattering is taken into account in the nephelometer measurements. Should the refractive index and proportions of aerosol particles in each size class (relative size distribution) remain stable during the measurement period, it results from equation (1) that $\sigma_{\text {scatt }, \lambda}$ would be proportional to $\sigma_{\text {neph }, \lambda}$ and correcting the nephelometer measurements to obtain $\sigma_{\text {scatt }, \lambda}$ would then simply involve multiplication by the following constant:

$$
\mathrm{C}_{\text {corr }}=\sigma_{\text {scatt }, \lambda} / \sigma_{\text {neph }, \lambda}=\frac{\int_{d=0}^{\infty} \sigma_{\mathrm{N}, \text { scatt }, \lambda}(\mathrm{d}, \mathrm{n}) \frac{\mathrm{dN}}{\mathrm{d} \log (\mathrm{d})} \mathrm{d} \log (\mathrm{d})}{\int_{\mathrm{d}=0}^{\infty} \mathrm{f}(\mathrm{d}, \lambda, \mathrm{n}) \sigma_{\mathrm{N}, \mathrm{scatt}, \lambda}(\mathrm{d}, \mathrm{n}) \frac{\mathrm{dN}}{\mathrm{d} \log (\mathrm{d})} \mathrm{d} \log (\mathrm{d})}
$$

It results from its definition that $\mathrm{C}_{\text {corr }}$ is larger than 1 . It is also easy to demonstrate that when the aerosol size distribution is available only above a minimal size $(0.3 \mu \mathrm{m}$, in the case of the OSA measurements), the value $\left(\mathrm{C}_{\text {corr,OSA }}\right)$ computed with this size distribution truncated on the left hand side is larger than $\mathrm{C}_{\text {corr }}$. Finally, one gets:

$$
1<\mathrm{C}_{\text {corr }}<\mathrm{C}_{\text {corr,OSA }}
$$

and in consequence,

$$
\sigma_{\text {neph }, \lambda}<\sigma_{\text {scatt }, \lambda}<\mathrm{C}_{\text {corr,OSA }} \sigma_{\text {neph }, \lambda} .
$$

[17] When the aerosol relative size distribution varies rapidly with time, $\sigma_{\text {scatt }, \lambda}$ must be computed from equation (1) in which $f(d, \lambda, n)$ is set equal to 1 for all size classes. When using the OSA size distributions instead of full ones, the importance of the underestimation deriving from the truncation of the smaller particles can be estimated numerically by comparing $\sigma_{\text {neph, } \lambda}$ measured at any time during the experiment to the result of its computation by equation (1) with the truncated size distribution.

[18] Another important aerosol characteristic that can be derived from the nephelometer measurements is the spectral dependence of $\sigma_{\text {neph }}$. This dependence is an intensive parameter in the sense that it depends on the aerosol relative size distribution and refractive index but, contrary to $\sigma_{\text {neph }, \lambda}$, not on the aerosol concentration. It is generally assumed that $\sigma_{\text {neph }}$ can be described in the visible spectrum as a power law of $\lambda$ :

$$
\sigma_{\text {neph }, \lambda}=\alpha \lambda^{-A_{\text {neph }}},
$$

where $\alpha$ is a constant, and $A_{\text {neph }}$ is the non dimensional Angström exponent. If, in order to cover the widest possible spectral range, one chooses to compute $A_{\text {neph }}$ from the nephelometer measurements at 450 and $700 \mathrm{~nm}$, one obtains

$$
\mathrm{A}_{\text {neph }}=-\log \left(\sigma_{\text {neph }, 450} / \sigma_{\text {neph }, 700}\right) / \log (450 / 700) .
$$

[19] Time series of $A_{\text {neph }}$ can be used to provide an insight on the types of aerosol associated with the various concentration peaks detected by either the TEOM or the nephelometer. Indeed, Mie theory shows that $A_{\text {neph }}$ increases when the size of the aerosol particles decreases. For instance, $A_{\text {neph }}$ values for fine anthropogenic aerosol encountered in polluted areas are typically larger than 1 , whereas $A_{\text {neph }}$ is close to nil, or even slightly negative, in regions dominated by coarser desert dust.

\subsubsection{Sun Photometer Measurements}

[20] Since it was implemented on 1 April on the roof of the SPDIC the Sun photometer (CIMEL, model CE 318-1, described by Holben et al. [1998]) has been measuring extinction by aerosols of solar radiation integrated over the height of the atmosphere, that is to say aerosol optical thickness (AOT), at 4 wavelengths $(441,670,870,1020 \mathrm{~nm})$. These data (available at http://aeronet.gsfc.nasa.gov/) have been screened according to a standardized procedure [Smirnov et al., 2000] to discard measurements that might possibly be contaminated by clouds. The value of the AOT is indicative of the importance of the columnar aerosol content. An Angström exponent $\left(\mathrm{A}_{\text {sun }}\right)$ can be defined to describe the spectral behavior of the AOT between the Sun photometer wavelengths closest to those of the nephelometer, namely 441 and $670 \mathrm{~nm}$ :

$$
\mathrm{A}_{\text {sun }}=-\log [\operatorname{AOT}(441) / \operatorname{AOT}(670)] / \log (441 / 670) .
$$

[21] As in the case of $A_{\text {neph }}$, the value of $A_{\text {sun }}$ provides information on the aerosol size distribution (averaged over the whole height of the atmosphere), and hence on its anthropogenic or dust-like nature.

[22] Other aerosol characteristics, such as its single scattering albedo $\left(\varpi_{0}\right)$ can be derived by inversion of the Sun photometer measurements [Dubovik and King, 2000]. For a given $\lambda$, this parameter, defined as the fraction of light extinction due to scattering alone, is typically less than 0.9 for particularly absorbing aerosols, such as those with a significant content in carbonaceous particles, and larger than 0.9 for mostly scattering ones.

\section{Results and Comments}

\subsection{Measurements at Ground Level}

\subsubsection{Meteorology}

[23] At ZBT, a strong diurnal cycle is observed for wind strength (Figure 4a). During the day, wind is relatively 

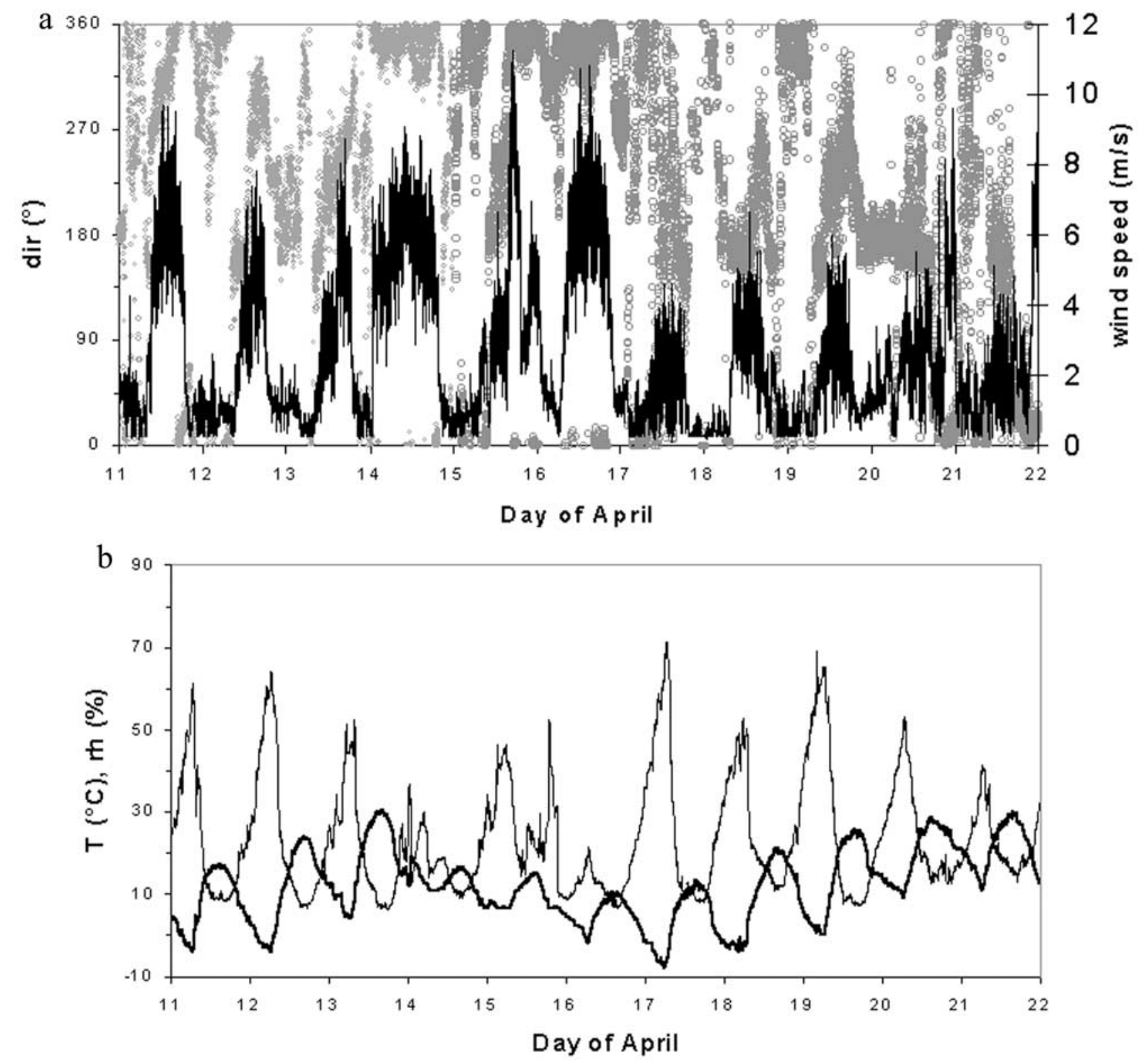

Figure 4. Meteorological data recorded at ZBT between 11 and 22 April 2002. (a) Wind speed (continuous line) and wind direction (open squares). Wind direction increases clockwise with $0^{\circ}$ corresponding to the north. (b) Temperature (bold line) and relative humidity (thin line). Note that ticks correspond to 00.00 AM.

strong (around $8 \mathrm{~m} / \mathrm{s}$ ) and essentially blows either from the north or from the south. In the latter case air masses sampled at ZBT come directly from the city of Yulin. Typically, wind speed decreases dramatically in the evening and remains low until early morning. A notable exception occurred around 00.35 AM on 14 April, when wind direction shifted brutally from 230 to $350^{\circ}$ and wind speed increased from less than $0.5 \mathrm{~m} / \mathrm{s}$ to more than $5 \mathrm{~m} / \mathrm{s}$ in less than $15 \mathrm{~min}$.

[24] Temperature and relative humidity $(\mathrm{RH})$, also follow a typical diurnal cycle (Figure 4b). Nonetheless, it can be noted that these cycles are perturbed at the onset of the 14 April dust storm. A sudden temperature rise of $4{ }^{\circ} \mathrm{C}$ accompanied by a $20 \%$ lowering in humidity, are observed at this time. It can also be added that, except on 4 particular nights, relative humidity remained less than $50 \%$. At such low $\mathrm{RH}$, aerosol optical properties are usually considered as independent of humidity variations, especially in the case of dust particles that are often assumed to be non-hydrophilic. Thus optical properties that will be derived from the ground based measurements will be considered as those of dry aerosols.

[25] Analyses of air mass back-trajectories show that all the air masses sampled at ZBT during the experiment had followed a route coming from the west or from the northwest. In this respect, the trajectory ending at ZBT on 14 April at 06.00 AM (UT, or 02.00 PM, local time) (Figure 5a), that is to say during a major dust storm (see below), is not different from the others. The main difference between situations is the speed at which air masses 
a

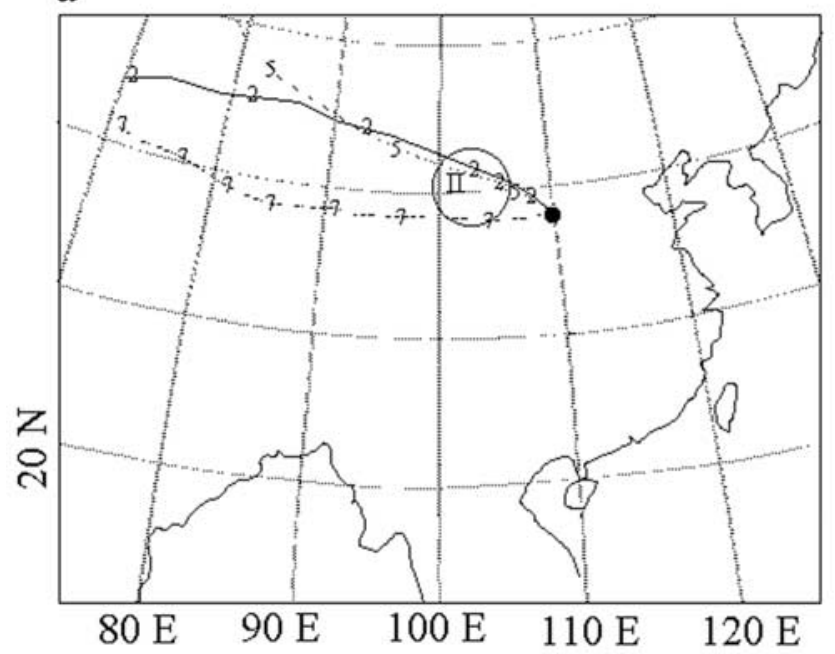

b

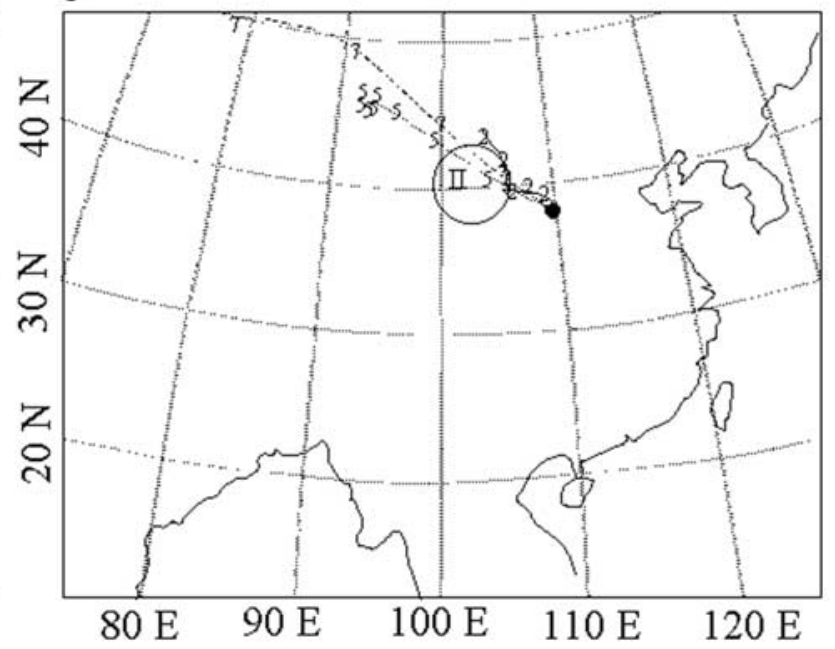

Figure 5. Back-trajectories of air masses sampled at ZBT on (a) 14 April, 06.00 (UT) and (b) 11 April, 12.00 (UT). UT is 8 hours behind local time. Positions of air masses have been computed every 6 hours at elevations $950,900,850,800,700,600$, and $500 \mathrm{hPa}$. For the sake of clarity, only levels $2(900 \mathrm{hPa}), 5$ $(700 \mathrm{hPa})$, and $7(500 \mathrm{hPa})$ have been reported. The "northwestern high desert sources" area has also been added on the map.

travel, and the more or less pronounced straightness of the trajectories. For example (Figure 5b), the ground-level air masses sampled at 08.00 PM (local time) on 11 April, had traveled much more slowly than the ones sampled during the dust storm. Moreover, a high-pressure system positioned only 200 or $300 \mathrm{~km}$ upwind of ZBT had communicated a clockwise twist to their trajectory. In these conditions, should the low-level air masses bring mineral dust to the measurement site on 11 April, their source could not be very far from Yulin. The situation is quite different on 14 April. Because the air masses had traveled fast and in a straight line before reaching the measurement site, dust sources could be located much further upwind than in the 11 April case.

\subsubsection{PM9 Concentrations}

[26] Results of PM9 mass concentrations measured by the TEOM between 9 and 21 April (Figure 6) show that the PM9 time dependence can be described as the result of the combination of two processes acting at different timescales. The first one, with a typical timescale of several days, corresponds to slow variations in the PM9 baseline above a minimum of about $30 \mu \mathrm{g} / \mathrm{m}^{3}$. The second process corresponds to sharp PM9 peaks, with duration ranging from an hour to less than a day, that are super-imposed on the previous variations. The large amplitude of these peaks can bring PM9 to values larger than the background by more than 2 orders of magnitude. This is for example the case for the PM9 absolute maximum $\left(4650 \mu \mathrm{g} / \mathrm{m}^{3}\right)$ recorded at 7.15 AM on 14 April during a major dust storm. On the basis of these observations, 3 kinds of situations can be distinguished over the duration of the TEOM measurements: Situations " $p_{i}$ " (where $i$ is the event number) when PM9 is close to its absolute minimum, situations " $\mathrm{d}_{\mathrm{i}}$ " corresponding to the sharp peaks, and situations in between when PM9, though larger than during $\mathrm{p}_{\mathrm{i}}$, is still close to the slow moving baseline. In order to assess the type of aerosol dominating each of these situations, results of the aerosol elemental composition analysis are going to be used.

\subsubsection{Type of Aerosol Dominating Various Periods}

3.1.3.1. Focusing on the 9-21 April Sampling Period

[27] During the TEOM measurement phase (9-21 April), 29 aerosol samples have been collected on Nuclepore filters and analyzed by XRF. Aluminum being generally considered as an element of purely crustal origin, its concentration time series can be used to estimate the importance of mineral dust concentrations. Those concentrations are found to be linearly correlated to PM9 concentrations averaged over the duration of the filter sampling:

$$
\text { PM9 }=17.7 \mathrm{Al}+33.3 \quad\left(\mathrm{r}^{2}=0.97 ; \mathrm{n}=29\right),
$$

where PM9 and $\mathrm{Al}$ are in $\mu \mathrm{g} / \mathrm{m}^{3}$. The strength of this correlation indicated by the high $\mathrm{r}^{2}$ value means that the increase in PM9 is mostly due to the increase in mineral dust concentration. Possible variations in anthropogenic aerosols concentrations have almost no effect on PM9 because dust particles are coarser than pollution ones, and thus control PM9 fluctuations. The PM9 $\left(33 \mu \mathrm{g} / \mathrm{m}^{3}\right)$ obtained in absence of dust $(\mathrm{Al}=0)$ can be interpreted as being representative of a pure pollution background. That this value is of the same order of magnitude as PM9 in situations $\mathrm{p}_{\mathrm{i}}$ could indicate that these periods are dominated by anthropogenic aerosols. Conversely, it seems reasonable to assume that during the strongest dust events the influence of pollution becomes minimal. Thus situations $d_{i}$ are probably representative of the purest possible mineral dust conditions that can be observed at ZBT. It can be noted that during these periods the Al/PM9 ratio is about 0.056, a value very close to the one reported for Chinese loess [Zhang et al., 1996]. In between situations $\mathrm{p}_{\mathrm{i}}$ and situations $\mathrm{d}_{\mathrm{i}}$, different degrees of aerosol mixing are expected. For studying separately the aerosol characteristics in dust, then 


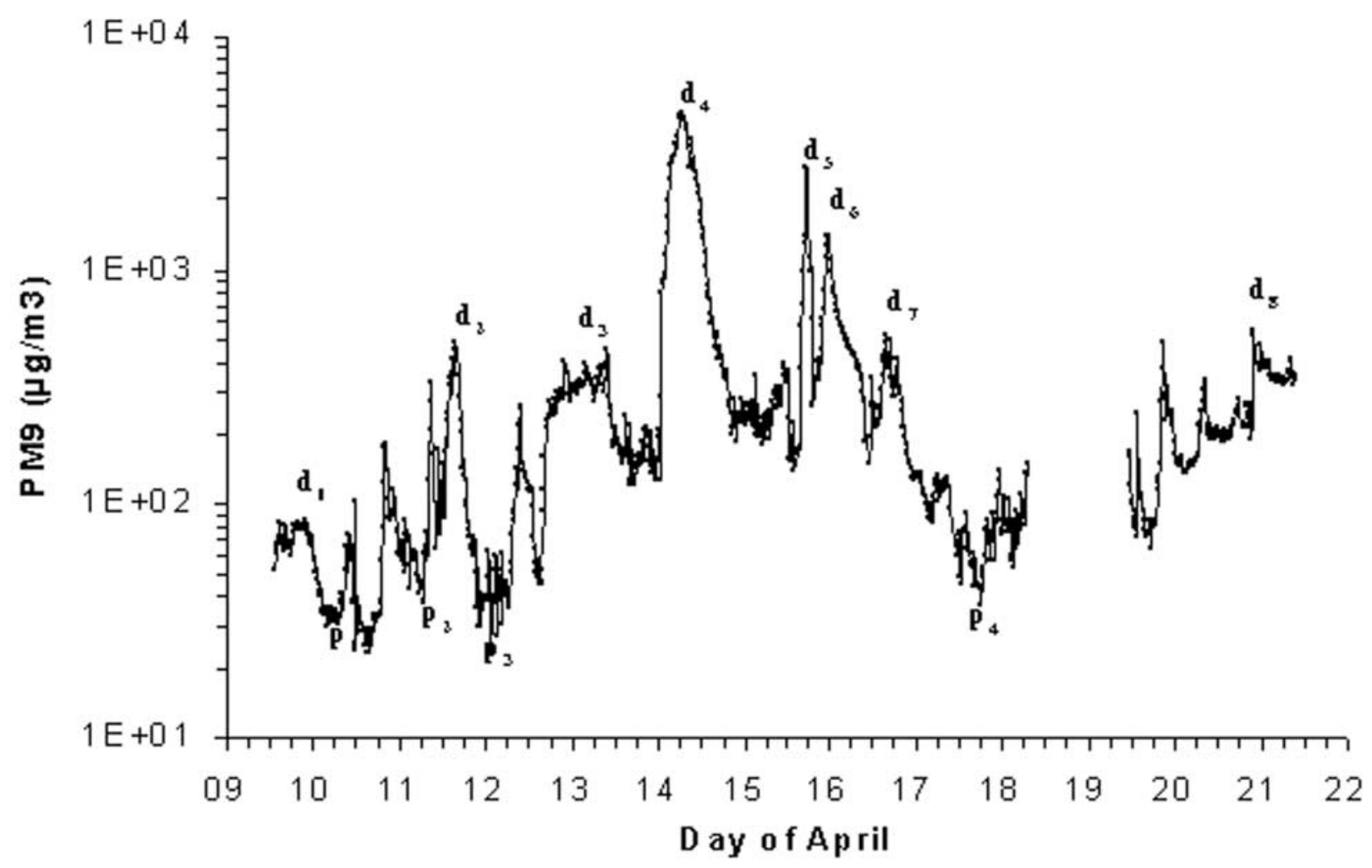

Figure 6. PM9 concentrations measured by the TEOM. On the basis of the $\mathrm{S} / \mathrm{Al}$ ratio, $\mathrm{p}_{\mathrm{i}} \mathrm{S}$ correspond to periods dominated by the pollution background, and $\mathrm{d}_{\mathrm{i}} \mathrm{s}$ correspond to those sharp mineral dust peaks during which at least one sample has been collected on filter and analyzed by XRF.

in pollution conditions, it is necessary to find a numerical criterion allowing separation of the time periods during which either one or the other of these aerosol types dominates.

[28] Because, on the one hand, $\mathrm{BC}$ and $\mathrm{S}$ are elements whose origin in the atmosphere can be mostly traced to human activities, and, on the other hand, $\mathrm{Al}$ is a purely crustal element, the $(\mathrm{BC}+\mathrm{S}) / \mathrm{Al}$ elemental ratio could be used as a proxy to estimate the importance of the aerosol anthropogenic component relative to the mineral one. However, it will be shown below that during the whole duration of the experiment $\mathrm{BC}$ and $\mathrm{S}$ concentrations remain proportional. In this case, either $\mathrm{BC} / \mathrm{Al}$ or $\mathrm{S} / \mathrm{Al}$ can be used instead of $(\mathrm{BC}+\mathrm{S}) / \mathrm{Al}$. Because the frequency of the filter sampling for XRF analysis of noncarbonaceous elements is higher than the one of filter sampling for carbonaceous component determination, $\mathrm{S} / \mathrm{Al}$ will be preferred to $\mathrm{BC} / \mathrm{Al}$. This ratio can be computed for $p_{i}$ and $d_{i}$ situations during which at least one filter sample has been collected. Eight such $d_{i}$ periods, and $4 \mathrm{p}_{\mathrm{i}}$ ones, exist that have been reported on Figure 6. S/Al ratios (Figure 7) obtained during $\mathrm{p}_{\mathrm{i}}$ conditions (4 filters) are all larger than 0.20 , whereas S/Al remains lower than 0.15 in $d_{i}$ conditions ( 15 filters). Thus $p_{i}$ and $d_{i}$ well correspond respectively to pollution-dominated and dust-dominated periods, and it appears that it is possible to separate these two types of conditions by the means of the $\mathrm{S} / \mathrm{Al}$ ratio.

[29] Results obtained with the rest of the filters (Figure 7) show that non- $p_{i}$ and non- $d_{i}$ situations mostly fall in polluted or mixed conditions (7 cases out of 9). This indicates that, apart when PM9, or Al, is large enough for crustal aerosol to really become dominant, mineral dust is often significantly contaminated by an anthropogenic component. More precisely, during the TEOM measurement period the anthropogenic component of the aerosol is always minimal (in the sense that $\mathrm{S} / \mathrm{Al}$ remains $<0.15$ ) when $\mathrm{Al}$ is larger than $13.2 \mu \mathrm{g} / \mathrm{m}^{3}$, or equivalently PM9 larger than $270 \mu \mathrm{g} / \mathrm{m}^{3}$. Nonetheless, it can be noted that dust dominated periods are also observed for $\mathrm{Al}$ concentrations as low as $3.93 \mu \mathrm{g} / \mathrm{m}^{3}$ when pollution levels are particularly low $\left(\mathrm{S}=0.362 \mu \mathrm{g} / \mathrm{m}^{3}\right.$, to be compared to the $2.63 \pm 1.68 \mu \mathrm{g} / \mathrm{m}^{3}$ average for the dust dominated periods).

[30] Also noteworthy is (1) that S/Al tends to become constant at high $\mathrm{Al}$ concentrations. Indeed, for the 5 filters collected on 14 and 15 April $\left(\mathrm{Al}>50 \mu \mathrm{g} / \mathrm{m}^{3}\right.$, on Figure 7) $\mathrm{S} / \mathrm{Al}$ is practically independent of $\mathrm{Al}$, which indicates that $\mathrm{S}$ is closely associated with mineral dust during this dust storm and (2) that the S/Al lower limit (0.05) is 5 times larger than the one found by Chiapello et al. [1999] for Saharan dust collected at Cape Verde Islands. A first possible explanation for these two observations could be that some S-containing minerals are present in the Chinese dust itself, and that this dust is richer in $\mathrm{S}$ than Saharan dust. A second possibility could be that mineral dust observed at ZBT during the dust storm had traveled over polluted areas before reaching our experimental site, and that its content in $\mathrm{S}$ had already been enhanced by incorporation of S-containing anthropogenic particles, presumably sulfates. For 


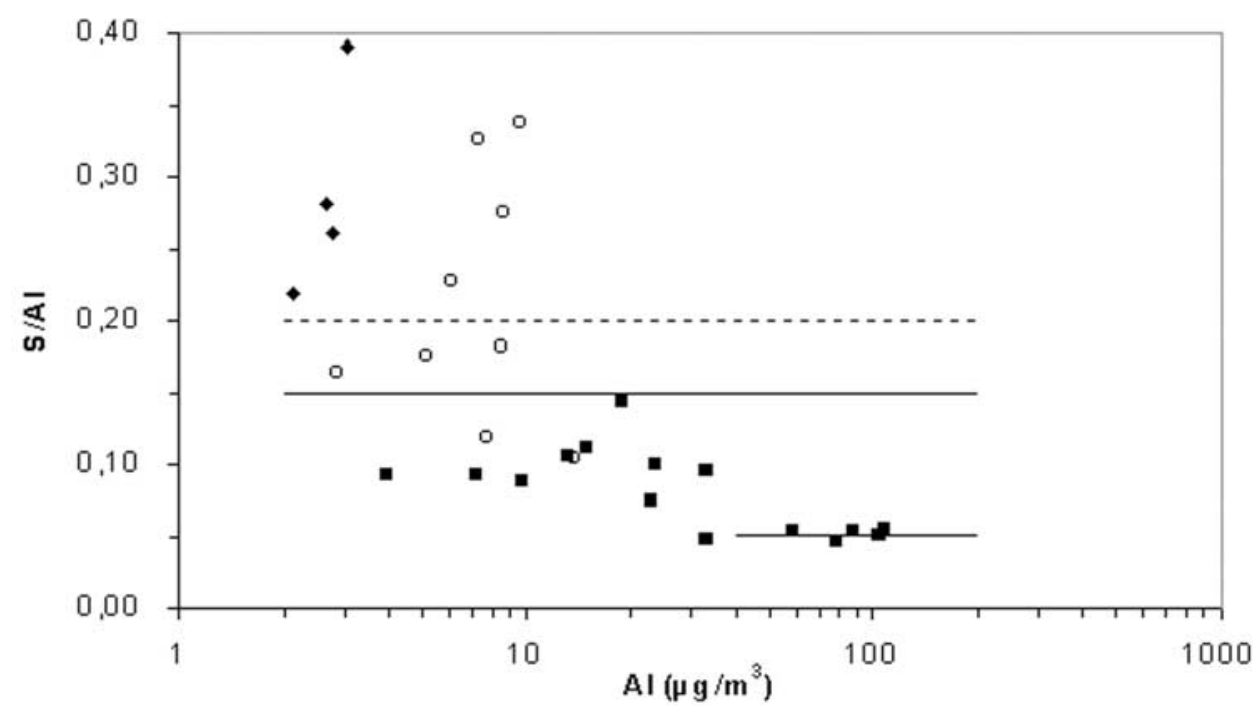

Figure 7. S/Al ratio determined from XRF analysis of aerosol samples collected during dust peaks (squares), pollution episodes (diamonds), and periods in between (open circles). The lowest value of S/Al ratio for pollution episodes $(\mathrm{S} / \mathrm{Al}=0.20)$ and the largest one for dust dominated episodes $(\mathrm{S} / \mathrm{Al}=0.15)$ are reported. The limit toward which $\mathrm{S} / \mathrm{Al}$ tends at high $\mathrm{Al}$ concentrations is also indicated.

lack of available data on $\mathrm{S} / \mathrm{Al}$ values for Chinese soils or aerosols, it is not possible to decide at this stage which of these 2 possibilities is the more likely.

\subsubsection{Results for the Whole Sampling Period (31 March to 23 April)}

[31] The S/Al method can be extended to the whole duration of the experiment. When doing so, 7 periods $\left(\mathrm{P}_{\mathrm{i}}\right)$ dominated by anthropogenic aerosols and 5 periods dominated by mineral dust $\left(\mathrm{D}_{\mathrm{i}}\right)$ can be distinguished (Table 2). Dust periods are typically observed in north or northwestern wind conditions. Those that only last a few hours $\left(D_{1}, D_{3}, D_{5}\right)$ coincide with already defined $\mathrm{d}_{\mathrm{i}}$ single dust peaks. They are inserted in pollution dominated periods when wind is either very low (especially at night, as during P4) or blows from the south, that is to say from Yulin city. Dust events lasting several days can be made of a rapid succession of the $d_{i}$ peaks (e.g, $\mathrm{d}_{4}$ to $\mathrm{d}_{7}$ between 14 and 17 April, i.e., during $\mathrm{D}_{4}$ ). In the short intervals separating these peaks, pollution cannot significantly alter the aerosol composition at ZBT because dust concentrations are still large, and, with wind being to the north, Yulin pollution cloud is not transported to the measurement site.

\subsubsection{Aerosol Composition}

[32] Among the 50 aerosol samples collected on Nuclepore filters (for XRF analysis) during the experiment, 15 where collected during uninterrupted pollution events, 24 during mineral dust ones (Table 2), and the rest during mixed situations. It has already be mentioned that, as expected for a mineral dust tracer, $\mathrm{Al}$ concentrations measured on pollution filters remained low $\left(<15.5 \mu \mathrm{g} / \mathrm{m}^{3}\right)$. In order to determine the elemental composition of the mineral aerosol relative to $\mathrm{Al}$, the $\mathrm{X} / \mathrm{Al}$ ratio can be computed for each major element ( $\mathrm{Si}, \mathrm{Ca}, \mathrm{Fe})$ analyzed by XRF and plotted against Al concentration (Figure 8). Results obtained for the other elements are reported in Table 3. In dust dominated situations, no significant difference in $\mathrm{Si} / \mathrm{Al}$, $\mathrm{Ca} / \mathrm{Al}$, and $\mathrm{Fe} / \mathrm{Al}$ ratios is observed between the various dust periods $\left(D_{1}\right.$ through $\left.D_{5}\right)$ that are all represented in the 24 dust filter series. This shows that the elemental composition of the mineral dust sampled at Yulin in April 2002 is relatively

Table 2. Time Boundaries of the Experimental Periods When Mineral Dust (D) or Anthropogenic Aerosol (P) Dominate ${ }^{\mathrm{a}}$

\begin{tabular}{|c|c|c|c|c|c|c|c|}
\hline$\underline{\text { Periods }}$ & Begins Date, dd/mm hh & End Date, dd/mm hh & Number of Filters & $\mathrm{Al}, \mu \mathrm{g} / \mathrm{m}^{3}$ & $\mathrm{~S}, \mu \mathrm{g} / \mathrm{m}^{3}$ & $\mathrm{~S} / \mathrm{Al}$ & Wind Direction \\
\hline $\mathrm{D}_{1}$ & $31 / 0311.00$ & $31 / 0318.20$ & 1 & 7,84 & 1,10 & 0.14 & - \\
\hline $\mathrm{D}_{2}$ & $06 / 0419.03$ & $09 / 0418.05$ & 8 & 23,87 & 1,13 & 0.05 & $\mathrm{~N}$ \\
\hline $\mathrm{D}_{3}$ & $11 / 0409.15$ & $11 / 0419.30$ & 2 & 8,48 & 0,76 & 0.09 & from $\mathrm{S}$ to $\mathrm{N}$ \\
\hline $\mathrm{D}_{4}$ & $14 / 0401.00$ & $17 / 0406.15$ & 12 & 45,84 & 2,86 & 0.06 & $\mathrm{~N}$ \\
\hline $\mathrm{D}_{5}$ & $20 / 0421.00$ & $21 / 0405.15$ & 1 & 18,88 & 2,73 & 0.14 & $\mathrm{~N}$ \\
\hline $\mathrm{P}_{1}$ & $01 / 0409.30$ & $03 / 0406.20$ & 4 & 7,80 & 2,19 & 0.28 & SSE \\
\hline $\mathrm{P}_{2}$ & $05 / 0411.00$ & $06 / 0406.20$ & 2 & 4,68 & 1,29 & 0.28 & - \\
\hline $\mathrm{P}_{3}$ & $10 / 0409.20$ & $11 / 0406.20$ & 2 & 2,45 & 0,60 & 0.24 & $\mathrm{~S}$ \\
\hline $\mathrm{P}_{4}$ & $11 / 0420.00$ & $12 / 0406.20$ & 1 & 2,14 & 0,47 & 0.22 & NW \\
\hline $\mathrm{P}_{5}$ & $17 / 0410.00$ & $18 / 0407.15$ & 2 & 2,86 & 0,98 & 0.34 & SW \\
\hline $\mathrm{P}_{6}$ & $19 / 0410.45$ & $20 / 0417.00$ & 3 & 7,32 & 2,05 & 0.28 & $\mathrm{~S}$ \\
\hline $\mathrm{P}_{7}$ & $21 / 0409.00$ & $22 / 0417.15$ & 1 & 5,12 & 1,93 & 0.38 & $\mathrm{~S}$ \\
\hline
\end{tabular}

${ }^{\mathrm{a}}$ These limits have been determined by the S/Al ratio method (see text for details). Average Al and S concentrations, and wind direction are also reported for each time period. 


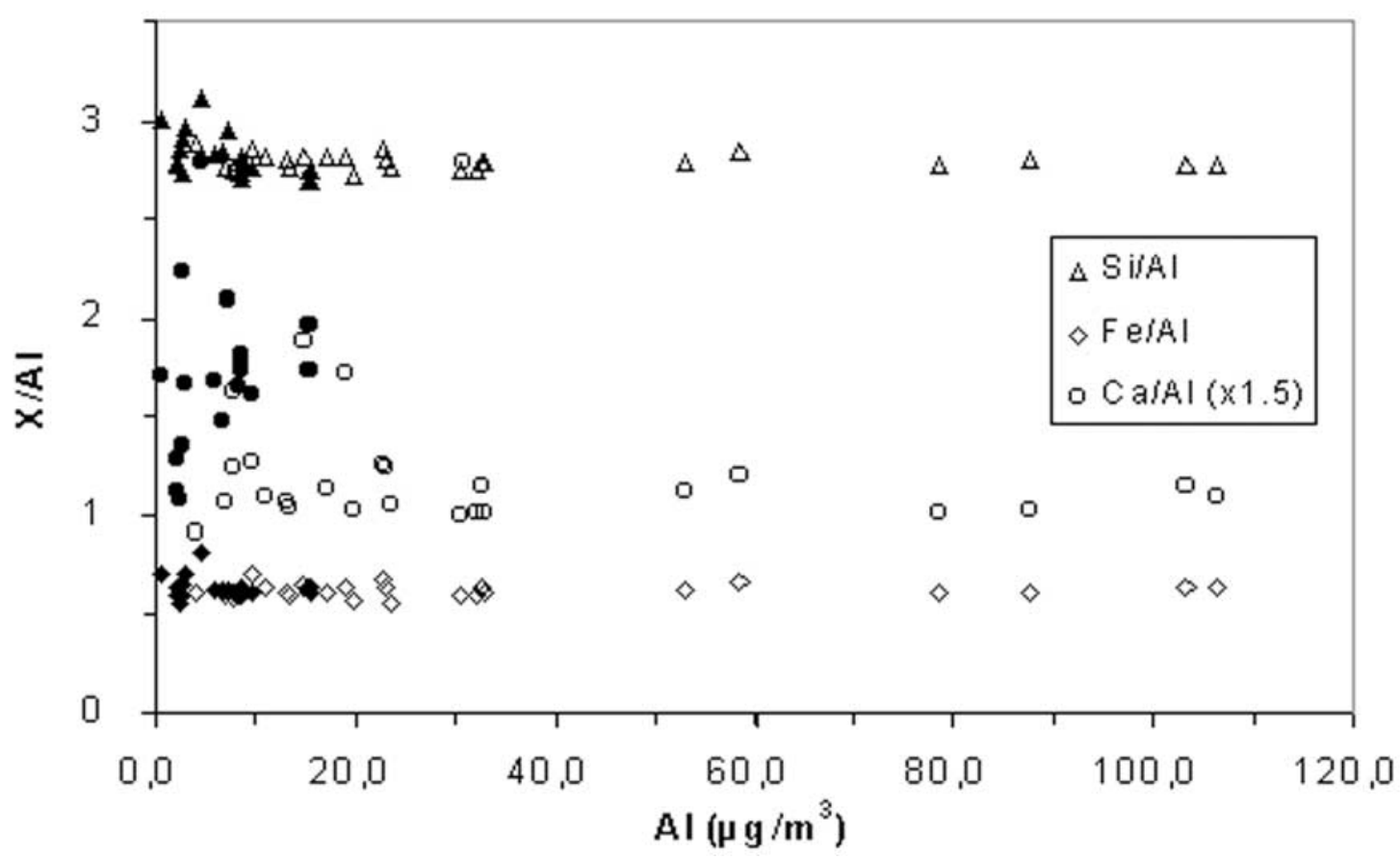

Figure 8. Elemental ratio $\mathrm{X} / \mathrm{Al}$ for major elements $(\mathrm{Si}, \mathrm{Ca}, \mathrm{Fe})$ derived from $\mathrm{XRF}$ analysis of aerosol samples collected during dust dominated periods (open symbols) and pollution events (filled symbols).

constant. Moreover, Zhang et al. [1996] have shown that the origin of dust in China can generally be traced to 3 geographically different desert sources by using $\mathrm{Fe} / \mathrm{Al}$ and $\mathrm{Mg} /$ $\mathrm{Al}$ elemental ratios. Values for these ratios obtained at ZBT (0.63, and 0.32 , respectively) compare quite well to those $(0.65$, and 0.31$)$ that were found by these authors to be typical of the "northern high dust sources" area. The possibility that dust events observed at Yulin may originate from these dust sources is also consistent with analysis of the air mass backtrajectories showing that the "northern high dust sources" (group II on Figure 1), are on the pathway of the low-level air masses that have been sampled at ZBT. Should this origin be confirmed, it would mean that dust had traveled several hundreds of kilometers, and crossed the highly industrialized area of the Huenghe (Yellow River) valley, before reaching the experimental site.

[33] Comparison between dust dominated and pollution dominated periods does not reveal any significant difference in $\mathrm{Si} / \mathrm{Al}$ and $\mathrm{Fe} / \mathrm{Al}$ ratios, indicating that the major source of $\mathrm{Si}$ and $\mathrm{Fe}$ is mineral dust in all cases. The situation is altogether different for $\mathrm{Ca}$. $\mathrm{Ca} / \mathrm{Al}$ is larger in pollution cases than in dust dominated periods. This enrichment reveals the presence in the local pollution aerosol of particles that are richer in Ca than "natural" mineral dust. An explanation for this could be the cement $(\mathrm{Ca} 0)$ particles released by the numerous construction sites in Yulin.

[34] Regarding $\mathrm{BC}$ and TC concentrations, the 16 dust samples collected on quartz filters during the experiment show a relatively high $\mathrm{BC} / \mathrm{TC}$ ratio $(0.33 \pm 0.12)$ for the measurement period. This result indicates that the carbonaceous component of the aerosol is mainly due to fossil fuel combustion. This is not surprising in a region where the use of coal is widespread in the industry as well as for domestic purposes. BC concentrations that are found to be most of the time between 0.9 and $4.9 \mu \mathrm{g} / \mathrm{m}^{3}$ (Figure 9) are also typical of polluted areas. For example, these values compare well to BC levels measured in urban areas in the western countries [Hitzenberger and Tohno, 2001; Ruellan and Cachier, 2001], or over the whole Indian subcontinent during the winter dry season [Alfaro et al., 2003]. More surprising is the large BC peak $\left(10.8 \mu \mathrm{g} / \mathrm{m}^{3}\right)$ associated with the 14 April major dust storm. At this time, $\mathrm{BC}$ concentration becomes

Table 3. Elemental Ratio Determined From XRF Analysis of Aerosol Samples Collected in Situations Dominated by Mineral Dust (24 Samples) or by Anthropogenic Emissions (15 Samples) ${ }^{\mathrm{a}}$

\begin{tabular}{ccccccc}
\hline & \multicolumn{3}{c}{ X/Al } & & \multicolumn{2}{c}{ X/Al } \\
\cline { 2 - 3 } Element, X & Dust & Pollution & & Element, X & Dust & Pollution \\
\hline $\mathrm{Si}$ & $2.79(0.04)$ & $2.83(0.11)$ & & $\mathrm{Ti}$ & $0.054(0.004)$ & $0.057(0.007)$ \\
$\mathrm{Al}$ & 1 & 1 & $\mathrm{Mn}$ & $0.015(0.002)$ & $0.015(0.003)$ \\
$\mathrm{Ca}$ & $0.79(0.15)$ & $1.14(0.26)$ & $\mathrm{P}$ & $0.013(0.001)$ & $0.015(0.002)$ \\
$\mathrm{Fe}$ & $0.63(0.04)$ & $0.64(0.06)$ & $\mathrm{Na}$ & $0.19(0.04)$ & $0.20(0.03)$ \\
$\mathrm{Mg}$ & $0.32(0.03)$ & $0.33(0.04)$ & $\mathrm{Cl}$ & $0.04(0.03)$ & $0.05(0.04)$ \\
$\mathrm{K}$ & $0.31(0.02)$ & $0.37(0.04)$ & $\mathrm{S}$ & $0.08(0.03)$ & $0.34(0.18)$ \\
\hline
\end{tabular}

\footnotetext{
${ }^{\mathrm{a}} \mathrm{Al}$ has been chosen as a reference, and standard deviation of the results are indicated between brackets.
} 


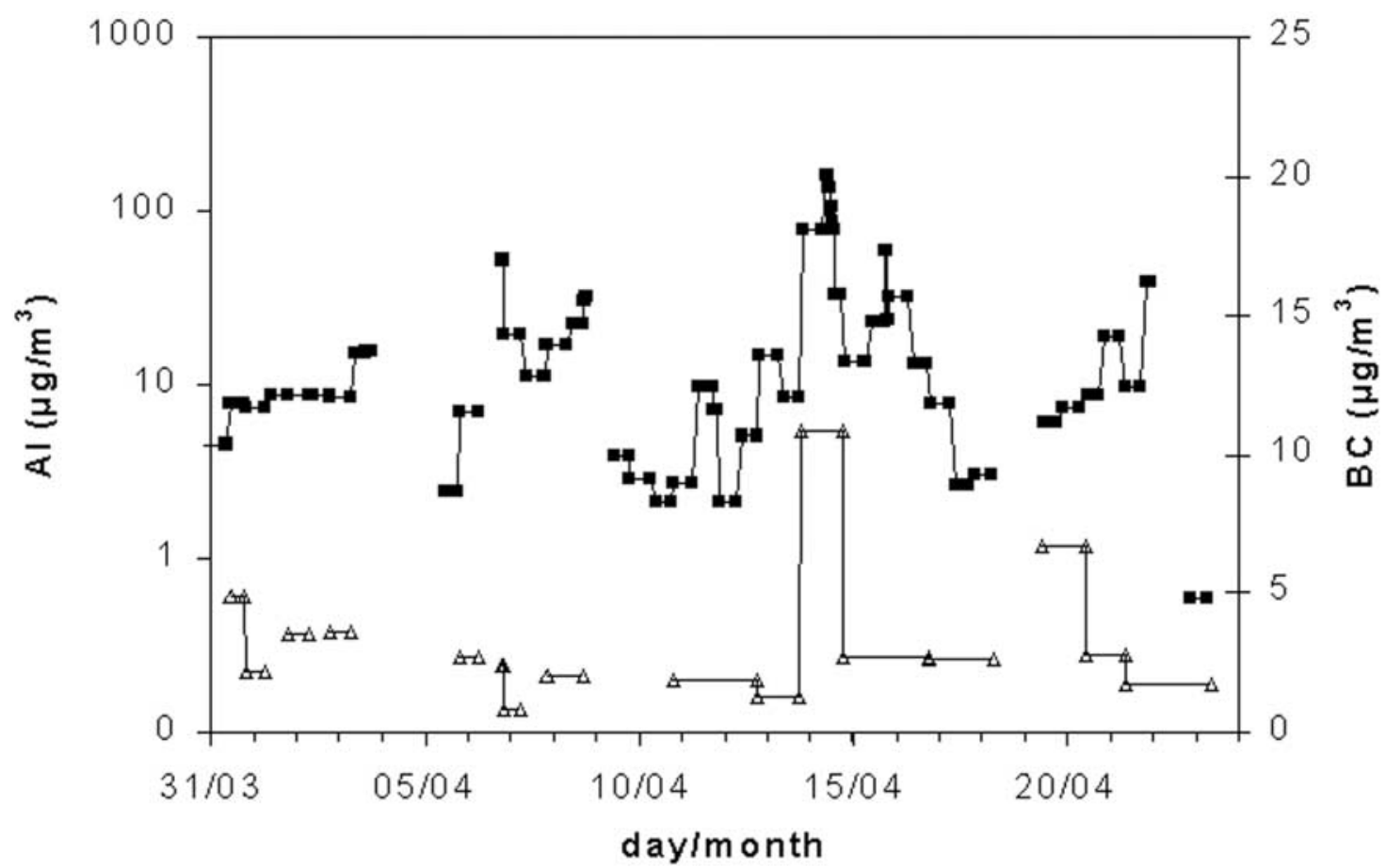

Figure 9. $\mathrm{BC}$ concentrations (open triangles) determined by thermal analysis of aerosol samples collected at ZBT. For the sake of comparison Al concentrations have also been reported (filled squares).

more than twice the usual background. To determine the reason for this sudden increase, the $\mathrm{BC} / \mathrm{Al}$ ratio has been computed for the duration of the experiment and plotted against Al. Results (Figure 10) show that for Al concentrations larger than about $15 \mu \mathrm{g} / \mathrm{m}^{3}$, that is to say in dust dominated conditions (see above), $\mathrm{BC} / \mathrm{Al}$ tends to stabilize at $0.11( \pm 0.05)$. This means that, even in the "purest" possible conditions, dust observed at Yulin is contaminated by a significant carbonaceous fraction. This observation supports the second theory developed above to explain that the lowest S/Al ratio measured at Yulin (during the 14 April dust storm) is larger than S/Al measured at Cape Verde

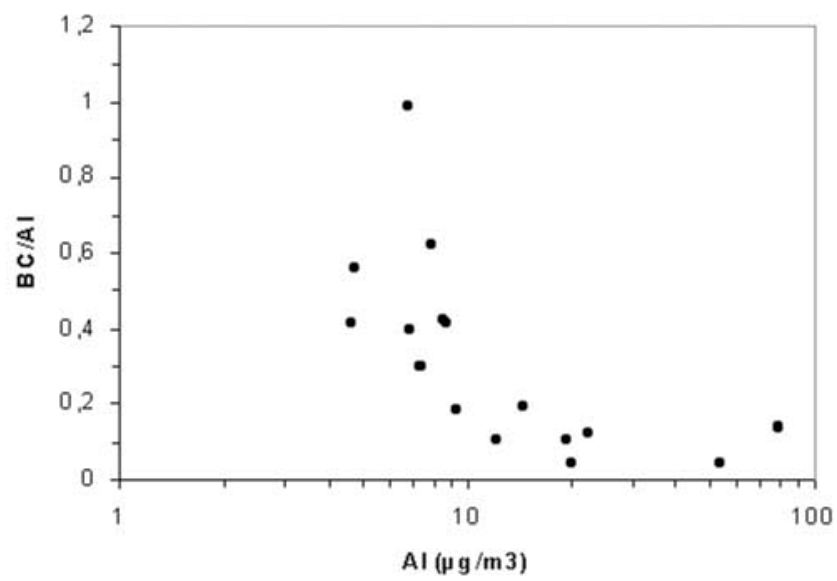

Figure 10. $\mathrm{BC} / \mathrm{Al}$ ratio plotted versus $\mathrm{Al}$. Even at very high dust concentrations this ratio does not tend toward 0 , indicating that mineral dust is intimately mixed with $\mathrm{BC}$ during dust storms. for Saharan aerosol, namely, that dust observed at ZBT on 14 April had been transported over polluted areas and mixed with anthropogenic aerosols before reaching the measurement site.

[35] By using the 16 periods for which $\mathrm{BC}, \mathrm{S}$, and $\mathrm{Al}$ concentrations are available at the same time, it is also possible to assess the apportionment of the anthropogenic

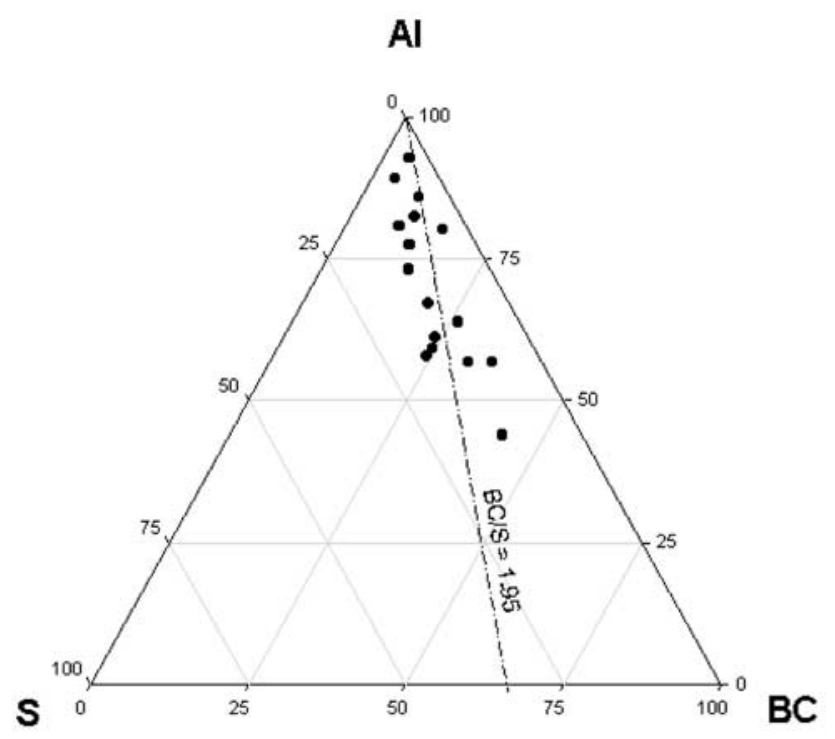

Figure 11. Relative composition of the 16 aerosol samples for which $\mathrm{BC}, \mathrm{S}$, and $\mathrm{Al}$ concentrations are available at the same time. 
Table 4. Angström Exponent and Relative Number Size Distributions Averaged Over the Experimental Periods Dominated by Mineral Dust $\left(\mathrm{D}_{\mathrm{i}}\right)$ or by Anthropogenic Aerosols $\left(\mathrm{P}_{\mathrm{i}}\right)$

\begin{tabular}{|c|c|c|c|c|c|c|c|}
\hline Periods & $A_{\text {neph }}{ }^{a}$ & $0.3-0.5 \mu \mathrm{m},{ }^{\mathrm{a}} \%$ & $0.5-0.7 \mu \mathrm{m}$ & $0.7-1.0 \mu \mathrm{m}$ & $1.0-2.0 \mu \mathrm{m}$ & $2.0-5.0 \mu \mathrm{m}$ & $>5 \mu \mathrm{m}$ \\
\hline $\mathrm{D}_{1}$ & $0.42(0.07)$ & $\mathrm{n} / \mathrm{a}$ & - & - & - & - & - \\
\hline $\mathrm{D}_{2}$ & $0.16(0.31)$ & $56(12)$ & $11(3)$ & $12(3)$ & $11(3)$ & $9(2)$ & $1.3(0.4)$ \\
\hline $\mathrm{D}_{3}$ & $0.19(0.18)$ & $56(10)$ & $12(2)$ & $11(3)$ & $10(3)$ & $9(2)$ & $1.6(0.6)$ \\
\hline $\mathrm{D}_{4}$ & $0.02(0.16)$ & 47 (11) & $13(2)$ & $14(3)$ & $13(3)$ & $11(2)$ & $1.7(0.7)$ \\
\hline $\mathrm{D}_{5}$ & $0.01(0.04)$ & $42(5)$ & $16(1)$ & $16(2)$ & $14(1)$ & $11(1)$ & $1.7(0.4)$ \\
\hline $\mathrm{P}_{1}$ & $0.69(0.10)$ & $82(4)$ & $8(1)$ & $5(1)$ & $3(1)$ & $2(1)$ & $0.4(0.1)$ \\
\hline $\mathrm{P}_{2}$ & $1.10(0.19)$ & $83(7)$ & $7(1)$ & $4(2)$ & $3(2)$ & $2(2)$ & $0.2(0.2)$ \\
\hline $\mathrm{P}_{3}$ & $1.15(0.14)$ & $86(3)$ & $7(1)$ & $4(1)$ & $2(1)$ & $2(1)$ & $0.2(0.1)$ \\
\hline $\mathrm{P}_{4}$ & $1.12(0.15)$ & $85(2)$ & $7(1)$ & $4(1)$ & $2(1)$ & $2(1)$ & $0.2(0.1)$ \\
\hline $\mathrm{P}_{5}$ & $1.13(0.15)$ & $88(3)$ & $6(1)$ & $3(1)$ & $2(1)$ & $1(1)$ & $0.2(0.2)$ \\
\hline $\mathrm{P}_{6}$ & $0.73(0.13)$ & 79 (10) & $8(2)$ & $5(2)$ & $4(2)$ & $3(2)$ & $0.5(0.3)$ \\
\hline $\mathrm{P}_{7}$ & $0.55(0.20)$ & $76(7)$ & $9(2)$ & $6(2)$ & $5(2)$ & $4(2)$ & $0.6(0.2)$ \\
\hline
\end{tabular}

${ }^{\text {a }}$ Expressed as standard deviation.

aerosol between its $\mathrm{BC}$ and $\mathrm{S}$ components. Figure 11 shows that the $\mathrm{BC} / \mathrm{S}$ ratio remains close to 2 , and this independently of the atmospheric load in $\mathrm{Al}$, or equivalently, in mineral dust. This could indicate that the relative composition of the pollution transported to ZBT during the dust events is similar to that of the pollution produced locally.

\subsubsection{Size Distributions and Angström Exponent}

[36] Though particle concentrations expressed in terms of number vary as much as the ones expressed in terms of mass during the experiment, the relative proportions of particles counted in each size class of the OSA seem to depend mostly on the aerosol type (Table 4). In situations dominated by anthropogenic aerosols, particles in the $0.3-$ $0.5 \mu \mathrm{m}$ size class contribute as much as $88( \pm 3) \%$ to the particles seen by the OSA. The low standard deviation of these measurements emphasizes the constancy of the corresponding size distributions. This could be explained by the fact that the processes responsible for the formation of the pollution haze measured at ZBT do not vary much over the measurement period. A consequence of this is that the Angström exponent measured by the nephelometer during the $\mathrm{P}_{\mathrm{i}}$ periods also remains approximately constant $(0.92 \pm 0.15)$. Whatever difference may exist between the $P_{i}$ periods can be explained by the varying degree of mixing with mineral dust. Indeed, Angström exponent is found to be remarkably constant and close to 1.13 (Figure 12) when Al concentrations are very low $\left(<5 \mu \mathrm{g} / \mathrm{m}^{3}\right)$, but it decreases at larger $\mathrm{Al}$ concentrations, that is to say when the importance of the mineral component of the aerosol increases. It results from this that the Angström exponent and size distributions representative of the purest anthropogenic aerosol sampled at ZBT are those found during periods $\mathrm{P}_{2}, \mathrm{P}_{3}, \mathrm{P}_{4}$, and $\mathrm{P}_{5}$ (Table 2, and Figure 12). Conversely, the aerosol is coarser during dust periods, and the Angström exponent is lower. More precisely, the proportion of particles in the $0.3-0.5 \mu \mathrm{m}$ range averaged over the dust events drops to $50( \pm 7) \%$, and the number of particles in larger size classes increases significantly. As a result, $A_{\text {neph }}$ is lower $(0.16 \pm 0.15)$ during $\mathrm{D}_{\mathrm{i}} \mathrm{s}$ than during $\mathrm{P}_{\mathrm{i}} \mathrm{s}$. This time, differences in $\mathrm{A}_{\text {neph }}$ and in size distributions between the various $D_{i}$ periods can be explained only in part by the various degrees of mixing of mineral and anthropogenic aerosols. At lower Al concentrations (Figure 12) $A_{\text {neph }}$ is indeed found to increase in keeping with the relative part played by the fine anthropogenic aerosol, but this fails to explain the differences between periods $\left(D_{2}, D_{3}, D_{4}\right.$, and $\left.D_{5}\right)$ for which $\mathrm{Al}$ is larger.

[37] In order to understand the reasons for the internal variability of measurements within single dust events, one of them may be examined in details. For this we have chosen $\mathrm{D}_{4}$, because this period lasted a little more than 3 full days, and it included the huge 14 April dust storm that began suddenly at 1.00 AM (Figure 13a). During this period, the fraction of particles counted between 0.3 and $0.5 \mu \mathrm{m}$ varied between $30 \%$ at the peak of the event and $70 \%$ between 4.00 and $7.00 \mathrm{AM}$ on $15 \mathrm{April}$, at a time when the development of the local pollution cloud was made possible by the nocturnal lowering in wind speed (Figure 13b). This confirms that even during periods when, according to the S/Al criterion, mineral dust prevails, a first explanation for the aerosol size distribution variability can still be found in the varying degree of mineral and anthropogenic aerosol mixing. An additional cause to this variability is illustrated on Figure $13 \mathrm{~b}$. When local wind speed becomes larger than a threshold of about $10 \mathrm{~m} / \mathrm{s}$, the fraction of particles larger than $5 \mu \mathrm{m}$ increases rapidly, as for example in the cases of peaks $\mathrm{d}_{5}$, and $\mathrm{d}_{7}$. At this time, dust with a strong coarse component is probably produced locally and mixed with the dust produced further upwind

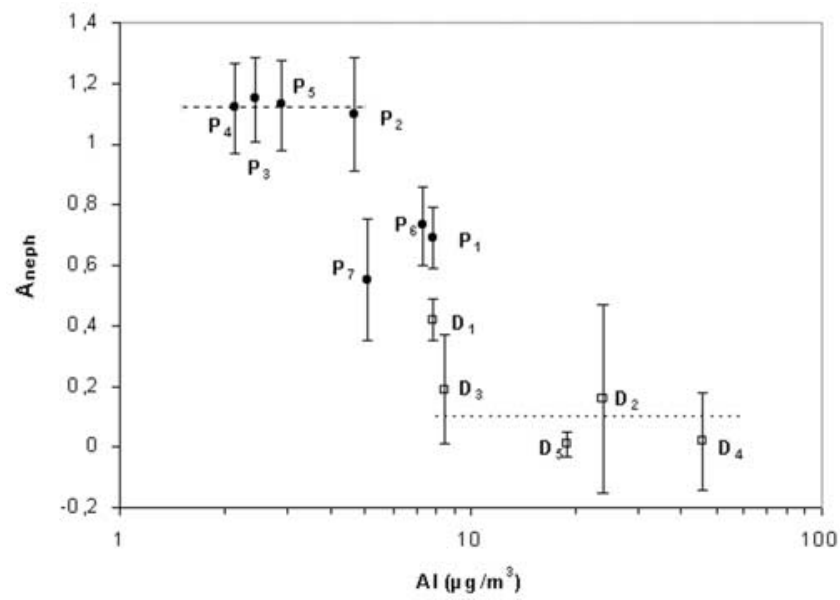

Figure 12. Aerosol Angström exponent for the pollution (P) and mineral dust (D) episodes. During $\mathrm{D}_{1}, \mathrm{P}_{1}, \mathrm{P}_{6}$, and $\mathrm{P}_{7}$, anthropogenic and crustal aerosols are clearly mixed. 

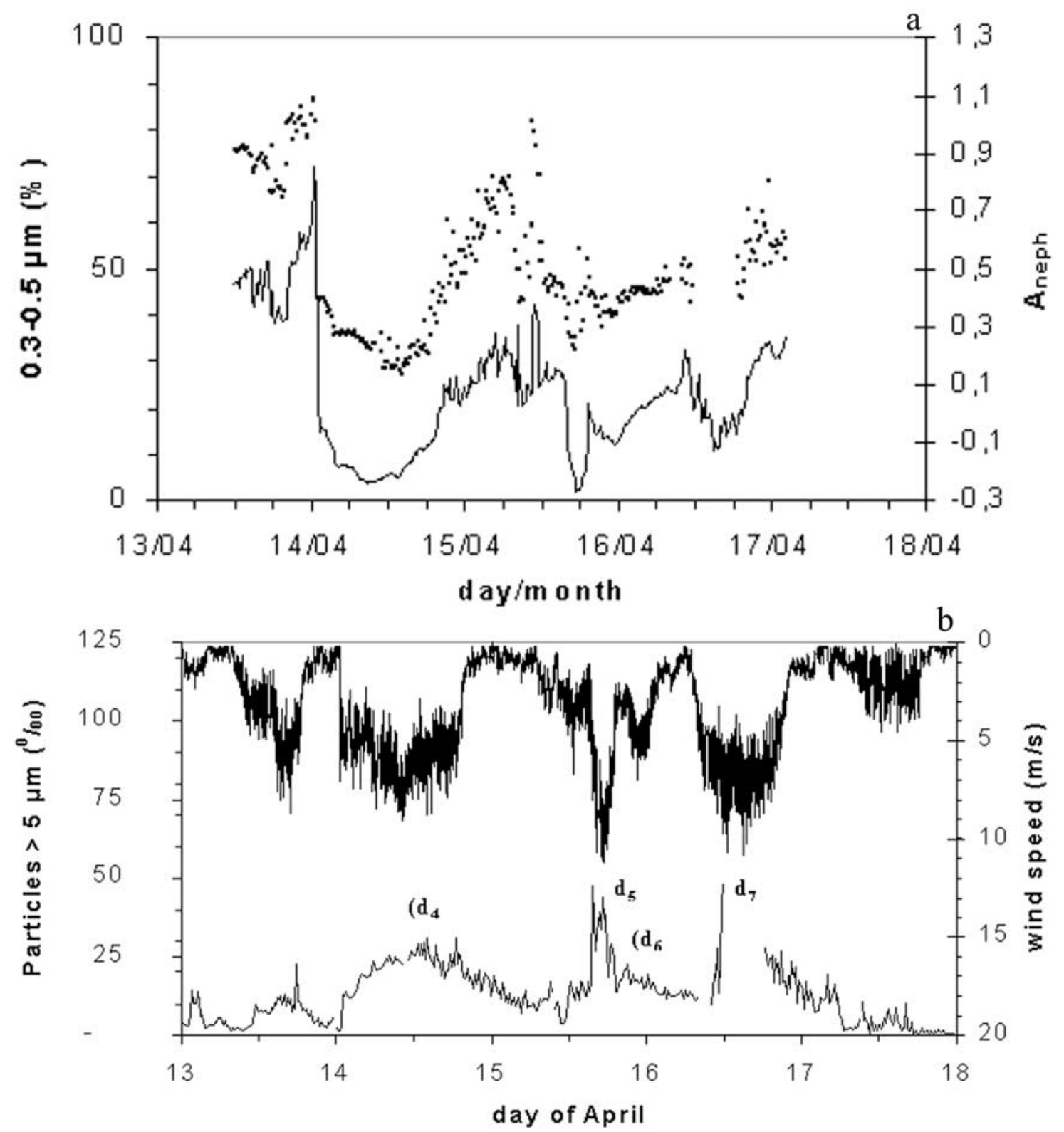

Figure 13. Parallel variations with time of (a) proportion of aerosol particles located in the finest size class $(0.3-0.5 \mu \mathrm{m})$ of the OSA (line with points), and $\mathrm{A}_{\text {neph }}$ (simple line) and (b) proportion of coarsest particles $(>5 \mu \mathrm{m}$, in $\%$ ), and wind speed at $10 \mathrm{~m}$ above ground.

and transported to the measurement site. The latter dust is finer than local one because during transport dry deposition processes tend to remove selectively coarse particles with high settling velocities from the aerosol. The Mie theory predicts that these variations in aerosol size distribution should have direct consequences on the spectral dependence of the aerosol optical properties. This is indeed the case: $A_{\text {neph }}$ variations follow closely those of the proportion in particles measured by the OSA in its finest size range (Figure 13a). It also reflects instantaneously the short-lived emissions of local coarse dust. The probability of occurrence of these outbursts is maximal in the afternoon, when wind speed tends to be larger than during the rest of the day. In summary, if the proportion of finest particles can be considered as a good indicator of the degree of mixing between dust and pollution, the rapid increase in the proportion of particles larger than $5 \mu \mathrm{m}$ is a good indicator of local dust production. By using this new criterion, it is found that dust peaks $\mathrm{d}_{2}, \mathrm{~d}_{5}, \mathrm{~d}_{7}$, and $\mathrm{d}_{8}$ are produced, at least in part, locally. This is not the case of other events, and especially $\mathrm{d}_{4}$, that can probably be explained by transport to ZBT of mineral dust produced further upwind.

[38] Figure 14 compares the relative size distributions of (1) mineral dust observed at ZBT during $\mathrm{d}_{4}$, that is to say at the peak of the 14 April dust storm in the "purest" possible case of transported dust, (2) mineral dust produced partly locally during $\mathrm{d}_{5}$, and (3) local pollution observed during the $\mathrm{P}_{4}$ period. In the latter case, particles are localized in one, or more, populations one of which is only partially "seen" by the OSA because its mean diameter is finer than 


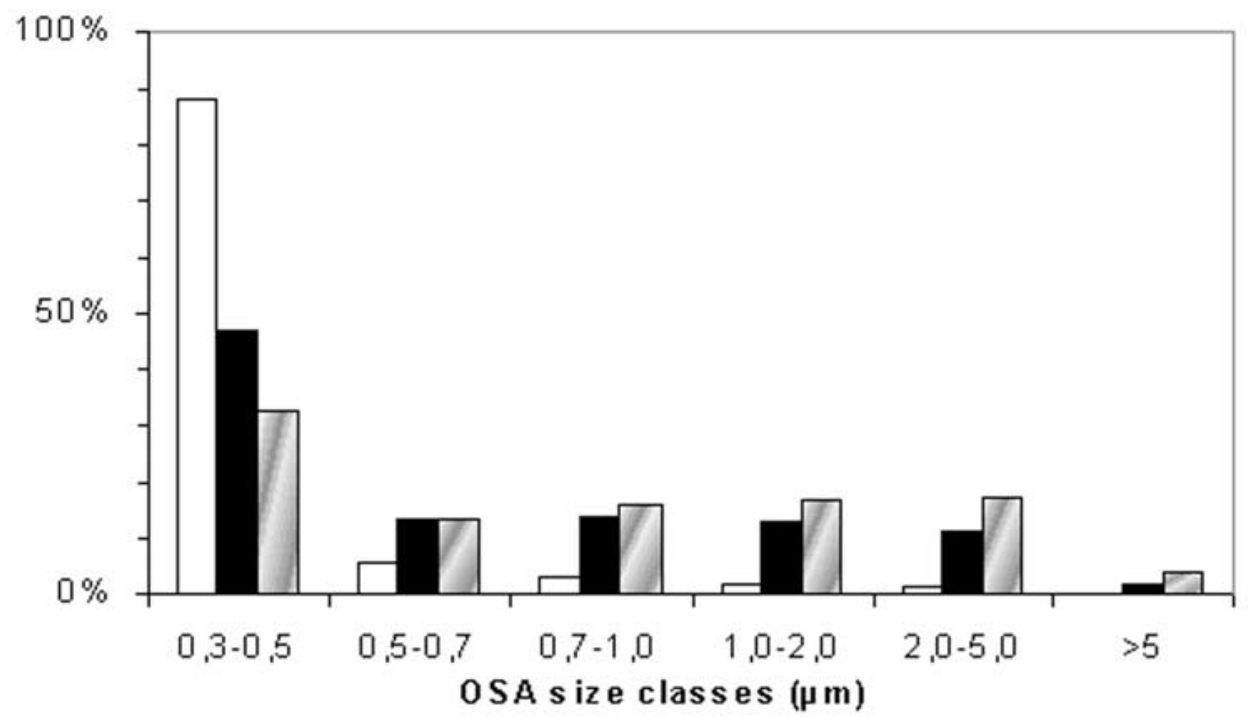

Figure 14. Average size distribution measured by the OSA during the $\mathrm{P}_{4}$ pollution events (white bars, $\mathrm{n}=80$ ). Two size distributions measured during the 3 days-long $\mathrm{D}_{4}$ period are also reported: the first one corresponds to transported dust $\left(\mathrm{d}_{4}\right.$, black bars, $\left.\mathrm{n}=10\right)$, and the second one to dust produced locally $\left(\mathrm{d}_{5}\right.$, shaded bars, $\left.\mathrm{n}=5\right)$.

$0.3 \mu \mathrm{m}$. Contrarily, a coarse population absent in pollution cases is fully detected by the OSA during dust events. This population has its mean number diameter in the $1.0-2.0 \mu \mathrm{m}$ size range. For local dust, the size distribution is shifted toward larger diameters because of the production of coarse particles. In both types of dust events, a fine population comparable to the one observed in the pollution cases is also partially detected by the OSA. Composition of particles constituting this fine mode is unknown, but they could correspond either to the pollution background, or to a mixture of this background with a particularly fine mineral dust population. In any case, the fraction of particles too small to be detected by the OSA must be larger during pollution events, when the aerosol is finer textured, than during dust ones.

\subsubsection{Mineral Dust and Anthropogenic Aerosols Scattering Properties}

\subsubsection{Raw Nephelometer Measurements}

[39] The scattering coefficients measured by the nephelometer between 31 March and 22 April display the same important degree of variability as the PM9 concentrations (data not shown). At times when TEOM and nephelometer

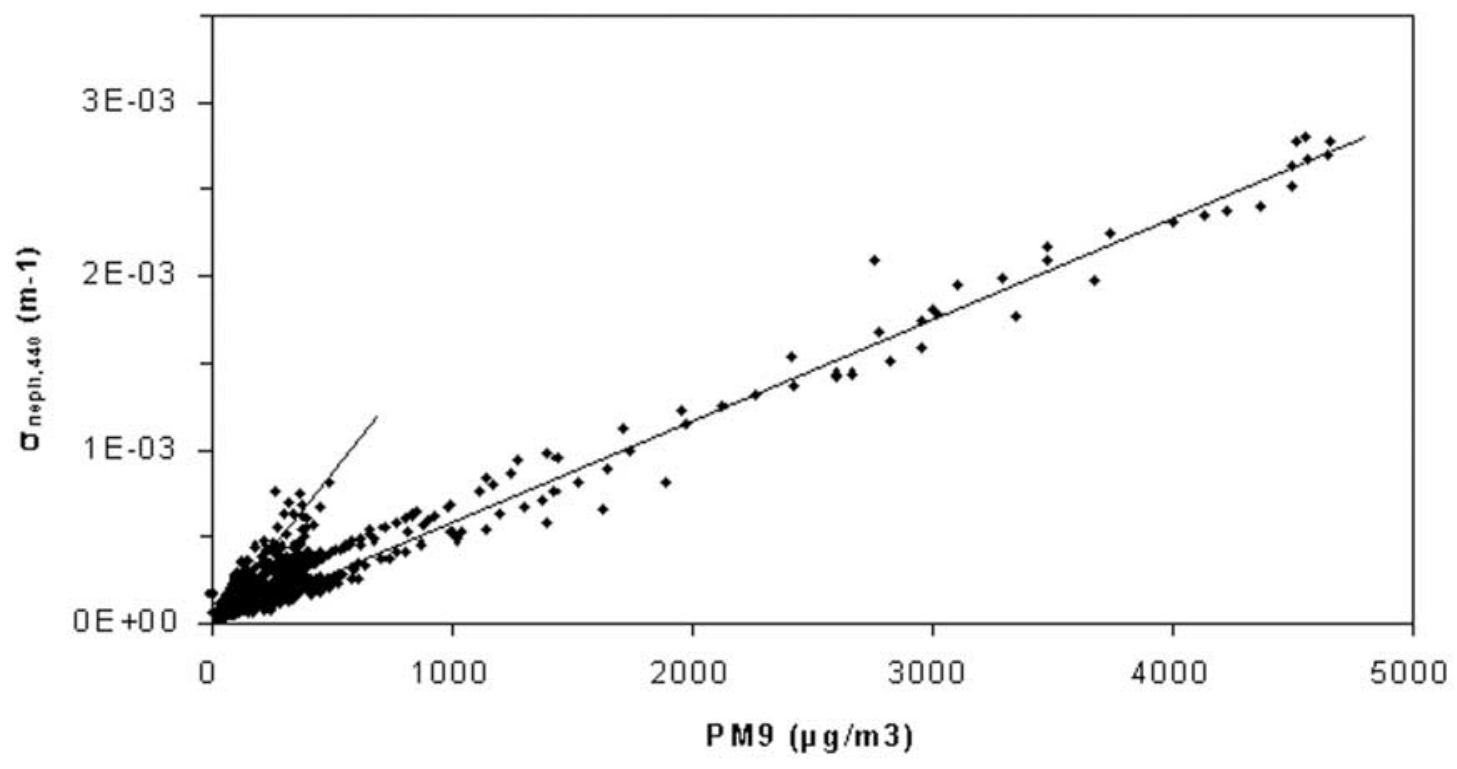

Figure 15. Scattering coefficient measured at $450 \mathrm{~nm}$ by the nephelometer versus concentrations in PM9 measured by the TEOM. Two different trends corresponding to dust-dominated and pollutiondominated situations can be observed. 
Table 5. Average Aerosol Mass Scattering Properties for Periods Dominated Either by Dust or by Anthropogenic Aerosols ${ }^{\mathrm{a}}$

\begin{tabular}{ccccc}
\hline Periods & $\begin{array}{c}\text { Estimated } \\
\text { Origin }\end{array}$ & $\mathrm{K}_{\mathrm{i}}, \mathrm{m}^{2} / \mathrm{g}$ & $\begin{array}{c}{\left[\sigma_{\text {scatt.450 }}\right],} \\
\mathrm{m}^{2} / \mathrm{g}\end{array}$ & $\begin{array}{c}{\left[\sigma_{\text {scatt,700 }}\right],} \\
\mathrm{m}^{2} / \mathrm{g}\end{array}$ \\
\hline $\mathrm{P}_{3}$ & local & $1.57 \pm 0.32$ & $1.65 \pm 0.08$ & 0.99 \\
$\mathrm{P}_{4}$ & local & $1.78 \pm 0.27$ & $1.86 \pm 0.09$ & 1.13 \\
$\mathrm{P}_{5}$ & local & $1.91 \pm 0.57$ & $2.00 \pm 0.10$ & 1.21 \\
$\mathrm{D}_{3}$ & local & $0.60 \pm 0.24$ & $0.89 \pm 0.08$ & 0.82 \\
$\mathrm{D}_{4}$ & transported (+local) & $0.70 \pm 0.16$ & $1.05 \pm 0.13$ & 1.04 \\
$\mathrm{D}_{5}$ & local & $0.62 \pm 0.08$ & $1.15 \pm 0.10$ & 1.14 \\
\hline
\end{tabular}

${ }^{\mathrm{a}} \mathrm{K}_{\mathrm{i}}$ are derived from raw (truncated) nephelometer measurements at $450 \mathrm{~nm}$. $\left[\sigma_{\text {scatt }, 450}\right]$ and $\left[\sigma_{\text {scatt, } 700}\right]$ are obtained by correcting nephelometer measurements for polluted periods $\left(\mathrm{P}_{\mathrm{i}}\right)$, or recomputed from Mie theory for dust periods $\left(\mathrm{D}_{\mathrm{i}}\right)$.

measurements overlap, a dual linear correlation exists between $\sigma_{\text {neph,450 }}$ and PM9 (Figure 15). This confirms our previous findings that two situations corresponding to two different aerosol types (mineral dust and pollution) can be distinguished over the measurement period. When dust dominates, the average slope $\left(\mathrm{K}_{1}\right)$ of $\sigma_{\text {neph }}$ versus PM9 plot is lower than the one $\left(\mathrm{K}_{2}\right)$ obtained in polluted situations. It must be noted that, though expressed in $\mathrm{m}^{2} / \mathrm{g}$, $\mathrm{K}_{\mathrm{i}}$ cannot be considered as being the effective aerosol mass scattering efficiency $\left(\left[\sigma_{\text {scatt }, \lambda}\right]_{i}\right)$. Indeed, $\mathrm{K}_{\mathrm{i}}$ has been defined from truncated nephelometer measurements (see above), and in consequence necessarily underestimates $\left[\sigma_{\text {scatt }, \lambda}\right]_{i}$. Nonetheless, for the sake of comparison with uncorrected values that might have been obtained during other experiments, $\mathrm{K}_{\mathrm{i}}$ have been determined (Table 5) for the clear-cut situations coinciding with the TEOM measurement period, and dominated either by mineral dust (periods $\left.\mathrm{D}_{3}, \mathrm{D}_{4}, \mathrm{D}_{5}\right)$ or by pollution aerosols $\left(\mathrm{P}_{3}, \mathrm{P}_{4}, \mathrm{P}_{5}\right)$. Situations in between, corresponding to periods when mineral dust and anthropic aerosols are well mixed, have not been taken into consideration.

\subsubsection{Retrieval of Mass Scattering Efficiencies}

[40] Because the $\mathrm{K}_{\mathrm{i}} \mathrm{s}$ underestimate the mass scattering coefficients that are needed to compute the aerosol effect on the atmospheric radiative transfer, it is necessary to retrieve these quantities for both pollution dominated, and mineral dust dominated periods. In the first case, the aerosol relative size distribution is practically constant (Table 4). It has been shown that it is then possible to correct nephelometer measurements by using a simple proportionality constant. $\mathrm{C}_{\text {corr,OSA }}$ is found to be 1.09 , and (4) shows that in these conditions, $\sigma_{\text {neph }, 450}<\sigma_{\text {scatt } 450}<1.09 \sigma_{\text {neph,450. }}$. Mass scattering efficiencies retrieved by this method, and averaged over the duration of the periods, have been reported for $\mathrm{P}_{3}$, $\mathrm{P}_{4}$, and $\mathrm{P}_{5}$ in Table 5 .

[41] These values that range from 1.65 to $2.00 \mathrm{~m}^{2} / \mathrm{g}$ at $450 \mathrm{~nm}$ are apparently substantially lower than those measured for pollution hazes in other parts of the world. Nonetheless, one has to be aware that comparisons may be hazardous due to differences in experimental conditions. For example, mass scattering efficiencies of $4.0( \pm 0.4) \mathrm{m}^{2} / \mathrm{g}$ and $3 \mathrm{~m}^{2} / \mathrm{g}$ have been measured, respectively, in the Yangtze delta region [Xu et al., 2002] and at Yulin (Xu et al., submitted manuscript, 2003), but these measurements were relative to PM2.5 while ours are relative to PM9. Thus our lower results can probably be explained, at least in part, by differences in size cutoff. Indeed, incorporation in the computation of coarse particles with large weight and low scattering efficiency results in a lowering of the computed overall mass scattering efficiency [Waggoner et al.,1981]. For instance, a mean and standard deviation of PM10 mass scattering efficiency of $2.3( \pm 1.6) \mathrm{m}^{2} / \mathrm{g}$ were measured by Bergin et al. [2001] in Beijing. Another important factor that may make comparison irrelevant is that nephelometer measurements are still rarely corrected for truncation errors. As seen above, this induces errors that increase with the atmospheric content in coarse particles, which is particularly crucial when mineral dust is involved.

[42] During dust periods size distributions are much more variable than during $\mathrm{P}_{\mathrm{i}} \mathrm{s}$. As a result, $\mathrm{C}_{\text {corr }}$ is not constant during $\mathrm{D}_{\mathrm{i}} \mathrm{s}$, and $\sigma_{\text {scatt }, \lambda}$ must be theoretically recomputed by using (1) in which $\mathrm{f}(\mathrm{d}, \lambda, \mathrm{n})$ is uniformly set equal to 1 . Then $\left[\sigma_{\text {scatt }, \lambda}\right]$ can be obtained as the slope of the $\sigma_{\text {scatt }, \lambda}$ versus PM9 plot. For assessing the order of magnitude of the underestimation of $\sigma_{\text {scatt }, \lambda}$, and hence of [ $\left.\sigma_{\text {scatt }, \lambda}\right]$, resulting from the use of the truncated OSA size distributions instead of the full aerosol size distributions, it is possible to compare $\sigma_{\text {neph }, \lambda}$ computed from equation (1) to direct nephelometer measurements. The average fraction of measured $\sigma_{\text {neph, } \lambda}$ retrieved by computation during $\mathrm{D}_{\mathrm{i}}$ periods $(84 \pm 13 \%)$, indicates that, on average, $\mathrm{PM}_{0.3}$ are responsible for about $16 \%$ of the nephelometer measurements in dusty conditions. Considering that the nephelometer truncation mainly affects detection of coarse particles (such as mineral dust ones) for which $\mathrm{f}(\mathrm{d}, \lambda, \mathrm{n})$ is lowest, the latter $16 \%$ fraction will become even less when $\mathrm{f}(\mathrm{d}, \lambda, \mathrm{n})$ are replaced by 1 for all OSA size classes in the $\sigma_{\text {scatt }, \lambda}$ computations.

[43] At $450 \mathrm{~nm}$, the $\sigma_{\text {scatt,450 }}$ obtained by this method during the $3 \mathrm{D}_{\mathrm{i}} \mathrm{s}$ when TEOM measurements are available $\left(D_{3}, D_{4}\right.$, and $\left.D_{5}\right)$ correlate linearly to the PM9 measurements, and the slopes of the plots provide an estimation of the aerosol mass scattering efficiency that are underestimated by between 0 and 16\%. Finally, it is found (Table 5) that during the purely local dust event $\left(D_{3}\right)$ the dust mass scattering efficiency relative to PM9 is significantly lower than during $\mathrm{D}_{4}$ and $\mathrm{D}_{5}$. It may also be noted that $\left[\sigma_{\text {scatt,450] }}\right.$ is larger than $K_{1}$ by $50 \%$ during $\mathrm{D}_{3}$ and $\mathrm{D}_{4}$, and by $85 \%$ during $\mathrm{D}_{5}$. These results emphasize the limits of the nephelometer measurements that seriously underestimate $\left[\sigma_{\text {scatt }, \lambda}\right]$ in the case of mineral aerosols whose size distributions are not only largely located in the supermicron size range, but also change rapidly. In this case it is impossible to correct the instrument measurements by using a simple proportionality constant. A correcting factor must be computed for each time period over which the size distribution can be considered as relatively constant, but this is in fact tantamount to using Mie theory to recompute aerosol mass scattering coefficients from the aerosol characteristics (complete size distribution, refractive index, and shape).

[44] For each pollution or dust period, $\left[\sigma_{\text {scatt }, 700}\right]$ can be obtained from $\left[\sigma_{\text {scatt,450 }}\right]$ and the average $A_{\text {neph}}$ :

$$
\left[\sigma_{\text {scatt }}, 700\right]=\left[\sigma_{\text {scatt }}, 450\right](700 / 450)^{-\mathrm{A}_{\text {neph }}}
$$

With $A_{\text {neph }}$ varying from 0.01 during $\mathrm{D}_{5}$ to 0.19 during $\mathrm{D}_{3}$ (Table 4$),\left[\sigma_{\text {scatt } 450}\right]$ is found to exceed $\left[\sigma_{\text {scatt } 700}\right]$ by between less than 1 to $8 \%$ in dust conditions. Nonetheless, it 

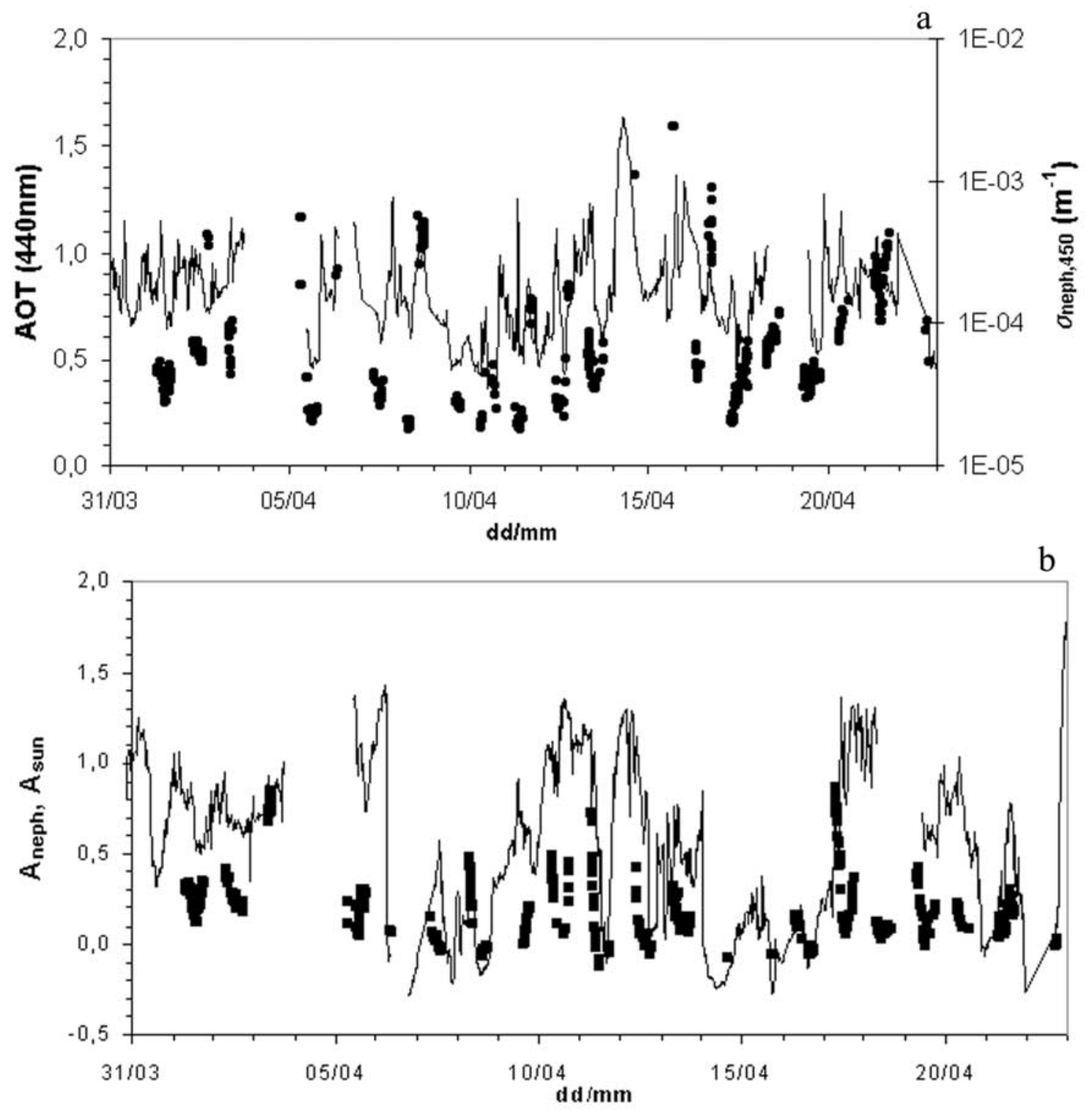

Figure 16. Comparison of vertically integrated aerosol properties, as measured by the Sun photometer, with nephelometer ground-level measurements. (a) Aerosol optical thickness (AOT) at $441 \mathrm{~nm}$ and $\sigma_{\text {neph,450 }}$ (continuous line) and (b) $\mathrm{A}_{\text {sun }}$ and $\mathrm{A}_{\text {neph }}$ (continuous line).

has to be noted that these averages do not well reflect that, at times of maximum dust concentrations, $A_{\text {neph }}$ may become negative, and then $\left[\sigma_{\text {scatt }, 450}\right]$ less than $\left[\sigma_{\text {scatt,700 }}\right]$.

\subsection{Vertically Integrated Measurements}

[45] Cloud screened AOT measured by the Sun photometer vary considerably during April (Figure 16a). In general, AOT maxima coincide with those detected at ground level by the nephelometer during $\mathrm{D}_{\mathrm{i}} \mathrm{s}$. For example, the highest AOT (1.59) to be recorded at $441 \mathrm{~nm}$ was measured on 15 April in the afternoon, that is to say at the same time than the secondary $\sigma_{\text {neph }}$ maximum observed one day after the 14 April maximum. Unfortunately, no measurement was made by the Sun photometer closest to the dust storm peak because the visibility was then so low that the instrument was unable to aim at the Sun. The simultaneity of $\sigma_{\text {neph }}$ and AOT maxima indicates that dust events are not limited to ground level, but must have a significant vertical extension. In order to determine whether characteristics of ground aerosols are representative of the atmospheric column or not, it is possible to compare Angström exponents derived from independent nephelometer and Sun photometer measurements (Figure 16b). Both exponents coincide during $\mathrm{D}_{\mathrm{i}}$ periods, showing that aerosol size distributions are relatively homogeneous along the vertical during dust events. At other times, the fact that $\mathrm{A}_{\text {sun }}$ never exceeds 0.87 and is systematically lower than $A_{\text {neph }}$ indicates (1) that the influence of mineral dust mixing with pollution denoted by the enhancement of $\mathrm{A}_{\text {neph }}$ is limited to ground level, and (2) that a layer of coarse particles, presumably dust, is always present above a ground-level pollution "bubble" developed by the city of Yulin. An indication of the vertical extension of the dust column during dust dominated periods can be provided by the aerosol "optical height scale" (OHS). 
OHS is defined as the height (in $\mathrm{m}$ ) of the homogeneous aerosol column having the same extinction coefficient $\left(\sigma_{\text {ext }}\right)$ as the one valid at ground level, and the same AOT as the one measured by the Sun photometer.

$$
\mathrm{OHS}=\mathrm{AOT} / \sigma_{\mathrm{ext}}
$$

[46] Since, by definition of the aerosol single scattering albedo $\left(\varpi_{0}\right)$ :

$$
\sigma_{\text {scatt }} / \sigma_{\text {ext }}=\varpi_{0}
$$

and (see above) for dust episodes,

$$
1.5 \sigma_{\text {neph }}<\sigma_{\text {scatt }}<1.9 \sigma_{\text {neph }}
$$

one finally gets

$$
\varpi_{0} \mathrm{AOT} /\left(1.9 \sigma_{\text {neph }}\right)<\text { OHS }<\varpi_{0} \mathrm{AOT} /\left(1.5 \sigma_{\text {neph }}\right) .
$$

[47] With $\varpi_{0}=0.89$ at $441 \mathrm{~nm}$ (see below), OHS is found to be $1700( \pm 500) \mathrm{m}$ during dust peaks, except in the case of $\mathrm{D}_{3}$ when it is much lower $(\sim 250 \mathrm{~m})$. This means that, most of the time, dust observed at Yulin is transported in a well developed layer, the bottom of which is at ground level. In turn, this is consistent with our previous findings that dust generally originates from relatively distant sources. $\mathrm{D}_{3}$ is a notable exception to this rule. The fact that during the short duration of this event (Table 2) dust is confined very close to the ground, and that local wind speed is then among the largest measured at ZBT (Figure 4a) suggest a purely local origin for this dust. This could also explain that the aerosol mass scattering coefficient is lower during $\mathrm{D}_{3}$ than during any other $\mathrm{D}_{\mathrm{i}}$. Indeed, PM9 mass concentration measured with the TEOM is very sensitive to the presence of coarse particles that are relatively more numerous during local dust events. In consequence, the ratio of $\sigma_{\text {scatt, } \lambda}$ to PM9, that is to say $\left[\sigma_{\text {scatt }, \lambda}\right]$, is naturally lower during these periods.

[48] Sun photometer measurements also provide a way of estimating the absorbing potential of mineral dust particles that has not been measured at ground level. Indeed, a data inversion procedure [Dubovik and King, 2000] can be used to retrieve the columnar aerosol single scattering albedo. Over $\mathrm{D}_{\mathrm{i}}$ periods, the average of $\varpi_{0}$ increases from $0.89 \pm$ 0.03 at $441 \mathrm{~nm}$ to $0.95 \pm 0.02$ at $873 \mathrm{~nm}$. This behavior compares well to the one of mineral dust observed in other parts of the world [Dubovik et al., 2002]. The $\varpi_{0}$ important values also show that, except at the lower end of the visible spectrum, mineral aerosols are relatively inefficient light absorbers and that their radiative effect is mainly due to their scattering properties.

\section{Summary and Conclusion}

[49] With the aim of determining the characteristics of mineral aerosols that may have an impact at regional or larger scale on radiative transfer, and hence on climate, measurements have been performed in April 2002 at ZBT, $10 \mathrm{~km}$ north of the city of Yulin. During this campaign several dust events were identified at ground level. They were interspersed with periods dominated by anthropogenic aerosols originating from nearby Yulin. Typical PM9 during these pollution outbreaks were below $100 \mu \mathrm{g} / \mathrm{m}^{3}$, significantly less than during the dust events when PM9 reached the exceptionally high value of $4650 \mu \mathrm{g} / \mathrm{m}^{3}$ at the peak of the 14 April dust storm. Ground-level and vertically integrated observations show that dust periods (DP) observed at Yulin can be sorted into 2 main categories. The first one (TD) corresponds to cases when dust is transported from relatively distant sources in a low-level layer with a typical vertical extension of $1.7( \pm 0.5) \mathrm{km}$. The second one (LD) corresponds to short-lived outbursts of local dust production occurring when wind speed at $10 \mathrm{~m}$ above ground becomes larger than a $10 \mathrm{~m} / \mathrm{s}$ approximate threshold. In fact, LD observed at Yulin were superimposed on TD events, except on one particular occasion $\left(\mathrm{D}_{3}\right)$ when the vertical extension of the dust plume was found to be very limited (about $250 \mathrm{~m}$ ). This shows that most of the dust events observed at Yulin can be described as deep layers of transported dust that may occasionally be modified close to the ground by injections of local dust. During these injections, the fraction of particles with a diameter larger than $5 \mu \mathrm{m}$ increases, but these coarse particles that are removed rapidly from the aerosol during transport are of little interest for assessing the climatic impact of mineral dust at relatively large scale. With this objective in mind, it appears clearly that dust characteristics that are relevant for climate studies are those prevailing during TD, and that attention should be focused on this type of events rather than on LD.

[50] No significant difference in mineral dust elemental composition was observed between the various TD. This tends to indicate that they all originated from similar sources. By using $\mathrm{Fe} / \mathrm{Al}$ and $\mathrm{Mg} / \mathrm{Al}$ ratios as tracers of the dust origin, it was determined that these sources were probably located in the "northwestern high desert sources." This finding is consistent with the back-trajectory analysis showing that the air masses sampled at ZBT had all traveled at low level over these potential sources. It is also in good agreement with the level at which dust is transported. Indeed, Sun et al. [2001] have shown that, contrary to dust originating from Taklamakan (area I, in Figure 1) that is transported at high level toward the east, dust raised in the gobi deserts of Mongolia and northern China are transported below $3000 \mathrm{~m}$ along a northwest/southeast route.

[51] For the transported dust the $\mathrm{BC} / \mathrm{Al}$ and $\mathrm{S} / \mathrm{Al}$ mass ratios were close to 0.1 and 0.05 , respectively. This means that before reaching the measurement site the mineral dust contained in TD had already incorporated carbonaceous and sulfate aerosols, probably when traveling over the industrialized Yellow River valley. During TD episodes, aerosol size distributions, mass scattering coefficients relative to PM9 and corrected for nephelometer truncation error (1.05 $\pm 0.13 \mathrm{~m}^{2} / \mathrm{g}$ ) were relatively constant. This was also the case of the Angström exponent $(0.19 \pm 0.18)$, and single scattering albedo $(0.95)$. This seems to indicate that the aerosol mixtures observed during these TD events were rather homogeneous upon arriving at ZBT. At this point it came in contact with the pollution produced at ground level by Yulin and its surroundings. This resulted in a build up of the aerosol anthropogenic component that was particularly visible when southern winds brought Yulin pollution to ZBT, or at night and in the early morning when wind speed was at its lowest and that the pollution cloud was able to 
develop more easily. At this time, ground-level measurements show that the proportion of fine particles in the aerosol dramatically increased, in parallel with the concentrations in anthropogeneous components $(\mathrm{BC}, \mathrm{S}, \ldots)$.

[52] Contrary to those of coarse dust particles produced by local wind erosion, the settling velocities of these fine pollution particles are very low and it is highly probable that turbulence would redistribute them eventually over the whole height of the transport layer. However, because ZBT was very close to pollution sources, this redistribution process had not been completed at the time of measurements. In consequence, the modifications of optical properties (mass scattering coefficient, Angström exponent) resulting from the pollution incorporation were still limited to a ground-level layer.

[53] Finally, the aerosol characteristics measured at ZBT during transport events were probably not exactly those of the pure dust produced in the "northern high desert sources" regions. These characteristics had already been enhanced (content in fine particles, mass scattering coefficient, Angström exponent) or lowered (single scattering albedo) by a first incorporation of anthropogenic particles during transport to the measurement site. In the same manner, further modifications of the aerosol properties are bound to happen each time they cross a polluted area. In consequence, gradients in aerosol characteristics probably exist along the main dust pathways. An observation network including several measurement sites similar to the one set up at ZBT in April 2001, and in April 2002, would be useful to document them.

[54] Acknowledgments. This work was supported in part by the French "Programme National de Chimie Atmosphérique" in the framework of the "Chimie-Climat" project, in part by the Chinese Academy of Sciences (grant KZCX2-305), and in part by the Chinese National Key Project of Basic Research (grant G2000048703). It has also been supported by the "Programme de Recherche Avancées" de coopération francochinoise (PRA T00-05, Cycle des poussières désertiques en Chine, L. Gomes and X. Y. Zhang). The authors would like to thank J. Zhang of the Shaanxi Province Institute of Desert Control, Y. Cheng, F. M. Mei, and H. Che of the Institute of Earth Environment in Xi'An for their technical and logistical help, and the PHOTONS/LOA and AERONET/NASA teams for calibrating the Sun photometer and processing its data. Thanks are also due to Y. Pointin for providing his back-trajectory scheme.

\section{References}

Alfaro, S. C., and L. Gomes, Modeling mineral aerosol production by wind erosion: Emission intensities and aerosol distributions in source areas, J. Geophys. Res., 106(D16), 18,075-18,084, 2001.

Alfaro, S. C., A. Gaudichet, L. Gomes, and M. Maillé, Mineral aerosol production by wind erosion: Aerosol particle sizes and binding energies, Geophys. Res. Lett., 25(7), 991-994, 1998.

Alfaro, S. C., A. Gaudichet, J. L. Rajot, L. Gomes, M. Maillé, and H. Cachier, Variability of aerosol size-resolved composition at an Indian coastal site during the Indian Ocean Experiment (INDOEX) intensive field phase, J. Geophys. Res., 108(D8), 4235, doi:10.1029/ 2002JD002645, 2003

Andreae, M. O., Climate effects of changing atmospheric aerosol levels, in World Survey of Climatology, vol. 16, Future Climate of the World, edited by A. Henderson-Sellers, pp. 341-392, Elsevier Sci., New York, 1995.

Bergin, M. H., et al., Aerosol radiative, physical, and chemical properties in Beijing during June 1999, J. Geophys. Res., 106(D16), 17,969-17,980, 2001.

Bodhaine, B. A., N. C. Ahlquist, and R. C. Schnell, Three-wavelength nephelometer suitable for aircraft measurement of background aerosol scattering coefficient, Atmos. Environ., Part A, 25(10), 2268-2276, 1991.

Cachier, H., M. P. Brémond, and P. Buat-Ménard, Determination of atmospheric soot carbon with a simple thermal method, Tellus, Ser. B, 41, 379-390, 1989.
Cautenet, G., F. Guillard, B. Marticorena, G. Bergametti, F. Dulac, and J. Edy, Modeling of a Saharan dust event, Meteorol. Z., 9, 221-230, 2000. Chiapello, I., G. Bergametti, B. Chatenet, F. Dulac, I. Jankowiak, C. Liousse, and E. S. Soares, Contribution of the different aerosol species to the aerosol mass load and optical depth over the northeastern tropical Atlantic, J. Geophys. Res., 104(D4), 4025-4035, 1999.

Dubovik, O., and M. D. King, A flexible inversion algorithm for retrieval of aerosol optical properties from Sun and sky radiance measurements, J. Geophys. Res., 105(D10), 20,673-20,696, 2000.

Dubovik, O., B. Holben, T. F. Eck, A. Smirnov, Y. J. Kaufman, M. D. King, and I. Slutsker, Variability of absorption and optical properties of key aerosol types observed in worldwide locations, J. Atmos. Sci., 59, 590608, 2002.

Gomes, L., G. Bergametti, G. Coudé-Gaussen, and P. Rognon, Submicron desert dusts: A sandblasting process, J. Geophys. Res., 95, 13,92713,935, 1990.

Hitzenberger, R., and S. Tohno, Comparison of black carbon (BC) aerosols in two urban areas-Concentrations and size distributions, Atmos. Environ., 35(12), 2153-2167, 2001.

Holben, B. N., et al., AERONET-A federated instrument network and data archive for aerosol characterization, Remote Sens. Environ., 66, 1-16, 1998.

Intergovernmental Panel on Climate Change (IPCC), Third Assessment Report, Climate Change 2001: The Scientific Basis, edited by J. T. Houghton et al., 944 pp., Cambridge Univ. Press, New York, 2001.

Losno, R., G. Bergametti, and G. Mouvier, Determination of optimal conditions for atmospheric aerosol analysis by X-Ray fluorescence, Environ. Technol. Lett., 8, 77-87, 1987.

Parungo, F., Z. Li, X. Li, D. Yang, and J. Harris, Gobi dust storms and The Great Green Wall, Geophys. Res. Lett., 21, 999-1002, 1994.

Pielke, R. A., and Y. Mahrer, Representation of the heated planetary boundary layer in mesoscale models with coarse vertical resolution, J. Atmos. Sci., 32, 2288-2308, 1975.

Ruellan, S., and H. Cachier, Characterisation of fresh particulate vehicular exhausts near a Paris highflow road, Atmos. Environ., 35(2), 453-468, 2001.

Smirnov, A., B. N. Holben, T. F. Eck, O. Dubovik, and I. Slutsker, Cloud screening and quality control algorithms for the AERONET data base, Remote Sens. Environ., 73, 337-349, 2000.

Sun, J., M. Zhang, and T. Liu, Spatial and temporal characteristics of dust storms in China and its surrounding regions, 1960-1999: Relations to source area and climate, J. Geophys. Res., 106(D10), 10,325-10,333, 2001.

Waggoner, A. P., R. E. Weiss, N. C. Ahlquist, D. S. Covert, S. Will, and R. J. Charlson, Optical characteristics of atmospheric aerosols, Atmos. Environ., 15, 1891-1909, 1981.

Willeke, K., and P. Baron, Aerosol Measurement: Principles, Techniques, and Applications, 876 pp., John Wiley, Hoboken, N. J., 1993.

Xu, J., M. H. Bergin, X. Yu, G. Liu, J. Zhao, C. M. Carrico, and K. Baumann, Measurement of aerosol chemical, physical and radiative properties in the Yangtze delta region of China, Atmos. Environ., 36, $161-173,2002$.

Xuan, J., and I. Sokolik, Characterization of sources and emission rates of mineral dust in northern China, Atmos. Environ., 36(31), 4863-4876, 2002.

Zhang, X. Y., G. Zhang, G. Zhu, D. Zhang, Z. An, T. Chen, and X. Huang, Elemental tracers for Chinese source dust, Sci. China, Ser. D, 39(5), $512-521,1996$.

S. C. Alfaro, B. Chatenet, A. Gaudichet, S. Lafon, and M. Maille, LISA, UMR-CNRS 7583, Université PVII/PXII, 61, avenue du général de Gaulle, F-94010 Créteil, France. (alfaro@lisa.univ-paris12.fr; chatenet@lisa.univparis12.fr; gaudichet@lisa.univ-paris12.fr; slafon@lisa.univ-paris12.fr; maille@lisa.univ-paris12.fr)

H. Cachier, LSCE, CEA-CNRS 1572, L'orme des merisiers 709, F-91191 Gif/Yvette Cedex France. (helene.cachier@cfr.cnrs-gif.fr)

G. Cautenet and F. Lasserre, LAMP, Université Blaise Pascal, Complexe scientifique des Cézeaux,BP 45, F-63170, Aubière, France. (g.cautenet@) opgc.univ-bpclermont.fr; f.lasserre@opgc.univ-bpclermont.fr)

L. Gomes, Meteo-France, CNRM/GMEI, 42, avenue Coriolis, F-31057 Toulouse, France. (laurent.gomes@meteo.fr)

J. L. Rajot, IRD/LISA, UMR-CNRS 7583, Université PVII/PXII, 61, avenue du général de Gaulle, F-94010 Créteil, France. (rajot@lisa.univparis12.fr)

X. Y. Zhang, State Key Laboratory of Loess and Quaternary Geology, Institute of Earth Environment, CAS, 10 Fenghui S. Rd, PO Box 17, Xi'An 710075, China. (xiaoye@loess.llqg.ac.cn) 